\title{
Macroeconomic effects of systemic stress: a rolling spillover index approach
}

TIHANA ŠKRINJARIĆ, Ph.D.*

\author{
Article $^{* *}$ \\ JEL: G1, G01, G20, E44, C32, E32 \\ https://doi.org/10.3326/pse.46.1.4
}

\footnotetext{
* The views presented in this paper are those of the author and do not necessarily represent the institution the author works at. The author is thankful to two anonymous referees whose comments have contributed to the final version of the paper.

${ }^{* *}$ Received: June 1, 2021
}

Accepted: November 6, 2021

Tihana ŠKRINJARIĆ

Croatian National Bank, Trg hrvatskih velikana 3, 10000 Zagreb, Croatia

e-mail: tihana.skrinjaric@hnb.hr

ORCiD: 0000-0002-9310-6853 
Abstract

This research focuses on the effects of financial instability on the rest of the economy. The article observes the dynamic changes of the shock spillovers between systemic stress and the rest of the German economy. In that way, the net emitters and receivers of shocks are observed throughout time, as previous research found that systemic stress is not always the predictor of other economic activity. The analysis utilizes Diebold and Yilmaz $(2009,2012)$ spillover index approach within the vector autoregression model. One step further is taken as well, as the changes of dynamics are observed throughout the entire period. As the macroprudential and monetary policymakers have to track the interrelationships between these variables over time, the approach in the study is straightforward and easy to interpret. The timing and intensity of the specific measures are important in practice, and such an approach enables the policymakers to meet these criteria.

Keywords: systemic risk, systemic stress index, financial system, monetary policy, macroprudential measures

\section{INTRODUCTION}

The interaction between systemic risk and the real economy has been in focus in the last few years (Giglio, Bryan and Pruitt, 2106; Tamási and Világi, 2011). This is especially true due to the problems the Global Financial Crisis has caused within banking systems and the financial system as a whole. The new problems stemming from the COVID-19 crisis have also modified the understanding of financial stability. It is important to obtain timely and insightful information about the spillovers of shocks to the real economy and their contribution to the financial stress of the whole system. This will enable policymakers to tailor their decisions more appropriately. However, the interaction between systemic risk and the real economy is still insufficiently explored. In particular, the interaction has not been sufficiently observed in the contexts of differing economic conditions. Some of the previous literature explores relationships that are linear and symmetrical ${ }^{1}$, which cannot realistically be assumed in the modelling process. That is why this research focuses on the changing interaction between systemic risk and the selected macroeconomic variables. The main focus is on obtaining better insights into the reactions of the real economy and the realization of systemic risk when different economic conditions obtain. The main methodological approach in this research is the spillover index of Diebold and Yilmaz $(2009,2012)$ within the VAR (vector autoregression) framework. There are several reasons why. The VAR approach of modelling is usual in the macroeconomic literature, as it is flexible, simple to interpret and the causalities between the variables of interest can be explored. Moreover, the directions between the shock spillovers (Blanchard and Quah, 1989; Lütkepohl, 1993; 2011) can be obtained. Secondly, the VAR approach allows for spillovers of shocks from the financial sector to the real economy, as

\footnotetext{
${ }^{1}$ The asymmetric behaviour of business cycles has been known as early as in Fisher (1933) and Keynes (1936), as well as earlier studies in Neftci (1984), Granger (2003) or Engle and Manganelli (2004); and of course, newer ones in Schüler (2014), White, Kim and Manganelli (2015), or Linnemann and Winkler (2016).
} 
found in Brunnermeier, Eisenbach and Sannikov (2012) or Christiano and Ikeda (2011); and from the real economy to the financial sector, as found in Delli Gatti et al. (2012). Another often-implemented approach is structural VAR (SVAR), which imposes some restrictions on the short and/or long-term interactions between economic variables. This can be based on stylized facts or on economic theory (see Boeckx, Dossche and Peersman, 2014). This is especially true for the analysis of monetary transmission mechanism (Christiano, Eichenbaum and Evans, 1999; Van Aarle, Garretsen and Gobbin, 2003). Thirdly, when focusing on the dynamic approach of modelling, it allows asymmetric behaviour in the observed relationships. Previous literature agrees that a nonlinear relationship exists between the macroeconomy and systemic risk. Early work includes Bernanke and Gerlter (1989), Bernanke, Gertler and Gilchrist (1999), or Kiyotaki and Moore (1997). Newer research includes Brunnermeier and Sannikov (2014), Montes-Rojas (2019), or He and Krishnamurthy (2019). That is why in this paper, a time-varying approach is allowed through the use of rolling window estimation of the VAR model with spillover indices. In that way, the dynamic changes of shock spillovers can be observed.

The contribution of this research is as follows. First of all, more than two basic variables are included in the analysis (such as the index of industrial production, IIP, and CSSI as in Chavleishvili and Manganelli, 2019). By excluding relevant variables in the VAR model, it can lead to omitted variable bias (see Christiano, Eichenbaum and Evans, 1996). Next, some approaches include more variables in the system but observe solely the static VAR model. In this research, dynamic changes of shock spillovers are observed between the systemic stress and the rest of the economy. Accordingly, the net emitters and receivers of shocks can be observed throughout time. This is because previous research found that systemic stress is not always the predictor of other economic activity (Cardarelli, Elekdag and Lall, 2011). Moreover, the majority of previous research work focuses on the sign (and/or magnitude) of the reactions of variables to systemic stress shocks. Here, we can observe when a variable receives and gives shocks to others. This is useful for economic policymakers, to track the interconnectedness between the systemic stress and the rest of the economy over time. This enables more timely reactions by both monetary and macroprudential policymakers. The empirical analysis will focus on Germany, due to the size of this economy within the EU and the EMU. Furthermore, the country experienced banking system instabilities in previous periods (Jahn and Kick, 2012). Thus, the CISS (Composite Indicator of Systemic Stress) as the financial stress indicator should have captured these instabilities. Furthermore, it should have affected the selected variables of interest, especially due to the banks playing a major role in the financial system (Schmidt, 2019). Moreover, the German financial system has a key role in the global economy (FSB, 2020). Finally, before moving on to other sections of the paper, a brief explanation is given of why the rolling window estimation of VAR approach is used, as opposed to the regime-switching or threshold VAR models. The switching models assume that the regimes, i.e., economic booms and busts, govern all of 
the variables in the same manner. Moreover, the switching approach is feasible for a small number of regimes (Schüler, 2014). Finally, by utilizing the rolling window approach, a smooth transition of the effects of one variable to another is allowed, alongside the smoother change of the spillover dynamics.

The main findings of the research include finding a time-varying relationship between the real economy and CISS. This finding indicates that the policymakers should take into consideration the effects of the systemic stress on variables of interest, and vice versa. The effects of policy stabilizations will have effects on the CISS variable as well. Findings confirm the existence of disproportional size and sign effects on the systemic stress and macroeconomic variables. Furthermore, as central banks have such reactions to increased systemic stress, the CISS variable in this case provides a good predictor of future interest rate movements. This is because the values of the spillover index from CISS to the interest rates, in this case, are high. This is in line with conventional views of reactions of monetary policy to financial instability. Furthermore, the effects of the inflation stabilization before the financial crisis contribute to the CISS variability. This is in line with previous findings of problems of focusing mostly on inflation targeting before the 2007-2008 financial crisis.

The rest of the paper is structured as follows. The second section deals with an overview of the related research important for this study. Then, the methodology description is given in the third section. Empirical results are analysed in the fourth section, with discussion and conclusion given in the final, fifth section.

\section{RELATED LITERATURE REVIEW}

This research belongs to the strand of literature that focuses on the effects of financial instability or distress on the rest of the economy. The majority of related research has been especially motivated by the financial crisis of 2007-2008, which is prominent in the introduction of many papers. Some of the papers state explicitly that the financial sector plays an important role in business cycle fluctuations, as found in Jerman and Quadrini (2012). Hakkio and Keeton (2009) constructed the Kansas City Financial Stress Index (KCFSI) to test its effects on the Chicago FED national activity index. Based on the VAR model results, the authors concluded that KCFSI could be a useful tool in deciding on when to remove liquidity from the system or add it. Hatzius et al. (2010) review existing measures of the systemic stress indices (FSI), build a new one, and compare the results of predictive capabilities of FSIs for future economic activity. A threshold VAR approach was utilized in Li and StAmant (2010). Here, the authors concentrate on questions such as: (a)symmetric effects of contractionary and expansionary monetary policy shocks and how the high versus the low systemic stress regime affects overnight interest rates. Based on Canadian data for the period 1981Q4-2006Q4, the estimated results indicate that inflation and output growth react stronger to contractionary than to expansionary monetary policy shocks. Jerman and Quadrini (2012) built a theoretical model regarding the effects of financial sector shocks and then tested it on real US data. The authors show that financial shocks were responsible for tightening the conditions of firms' credit in the economic downturns of 1990-1991 and the latest 
financial crisis. The analysis was conducted on US data, with several important findings, besides that mentioned: monetary policy contractions had negative output effects, with small liquidity effects. Jahn and Kick (2012) constructed a forward-looking indicator of the German banking system so that it can be used in the identification of macroprudential early warning indicators. Bank-level data were used to perform the analysis, with a panel regression approach for the period 1995-2010. Interesting findings are that asset price indicators, leading indicators of business cycles, and monetary indicators can be reliable preceding indicators for instability in the banking system itself.

In Van Roye (2014), the author constructs a financial stress market indicator (FSMI) and analyses the effects of systemic stress on economic activity. A small Bayesian VAR was utilized from a methodological standpoint to obtain information on the forecasting capabilities of an FSMI for GDP growth. Mallick and Sousa (2013) performed a detailed analysis of systemic stress in the Euro-zone (period 1980Q1-2008Q1) via Bayesian SVAR and sign-restriction. This research has as its main findings that unexpected variations in systemic stress have an important role in the explanations of output fluctuations, with contractionary monetary policy worsening systemic stress conditions. This had a result of long periods of low interest rates that contributed to asset price increases observed in the financial crisis of 20072008. Hubrich and Tetlow (2014) focus on the US data and the FED Financial Stress Index (FSI) within the regime-switching VAR to find that the conventional monetary policy is effective during the period of high systemic stress.

Hartmann et al. (2015) a research paper close to this one. The authors observe the effects of systemic risk shocks on the euro area macroeconomy. In the mentioned research, the methodological approach is that of regime-switching VAR. Based on the data on the output growth, interest rate, CISS, and (nominal bank) loans growth rate (period: January 1987 - December 2010), the results are interesting; when the euro area undergoes periods of high systemic stress, its shocks are greater than in tranquil times. The assumption of one regime (i.e., linear models) cannot capture such dynamics. Kremer's (2015) paper is also close to this research. Here, the author utilizes the VAR model and the direct and indirect Granger causality patterns of Hsiao (1982). The idea is to explore the relationship between the conventional, unconventional measures of monetary policy and the CISS indicator for the total euro area. The contribution of this research is found in an extensive robustness of the results testing. The main findings included the following. The CISS contributed to the dynamics of the macroeconomy and significantly affected the action of the monetary policy (in terms of policy rates, and the ECB, European Central Bank, balance sheet). However, the author admitted that the standard linear VAR approach in the analysis ignores potential nonlinearities, and this should be explored in future work more. Giglio, Bryan and Pruitt (2016) focused on the US, UK, and euro area data (differing periods, depending on the data availability). These authors focus on how systemic risk affects future macroeconomic movements, in terms of quantile regression and Bloom's (2009) VAR. 
The findings indicate that the selected systemic risk measures have significant predictive power on downside quantiles of the industrial production growth. It was concluded that the systemic risk is an asymmetric phenomenon with nonlinear behaviour; with the predictive power of the Federal Funds rate (rise of the risk leads to a large drop of the mentioned rate).

Among more recent papers is that of Chavleishvili and Manganelli (2019), in which authors explicitly focus on the QVAR (quantile VAR). The idea is to observe the results for the purposes of stress testing. Linear VAR and the $Q$ approach are contrasted on real data so that the possible differences can be seen. More precisely, the linear model cannot capture the asymmetric transmission of shocks from one variable to another. However, the authors observed only a bivariate VAR, in which the CISS and the euro area industrial production growth were included as the main variables (period: January 1999 to July 2018). Galán (2020) focused on the panel QVAR to identify the benefits of macroprudential policy on GDP growth. More specifically, the focus was done on the left-tail of the GDP growth distribution. The approach used by this study is to examine how (constructed measures) of macroprudential policies affect GDP growth, but in accordance with the position in the financial cycle and the time elapsed from the implementation of an instrument and the type of the instrument itself.

To summarize, the body of research is obviously growing. This is due to the problems that emerged not only after the global financial crisis of 2007-2008, but due to the pandemic problems and uncertainties that have arisen. The need to obtain better insights into financial (in)stability and macroeconomic sectors is higher than ever, However, many aspects of the macroprudential policies are still in the infancy phase. An analysis of the shock spillovers among the variables of interest, with the inclusion of the asymmetry assumption that has been recognized for a long time, could enhance tailoring of policies in the future.

\section{METHODOLOGY DESCRIPTION}

The main methodology used in this study is described by following Lütkepohl (1993; 2006; 2010) and Diebold and Yilmaz (2009; 2012). A stabile $\operatorname{VAR}(p)$ model of $N$ variables is considered in the matrix form: $y_{t}=v+A_{1} y_{t-1}+A_{2} y_{t-2}+\ldots$ $+A_{p} y_{t-p}+\boldsymbol{\varepsilon}_{t}$, where $\boldsymbol{y}_{t}$ is the $N \times 1$ vector of dependent variables, $A_{i}$ are the $N \times N$ matrices of coefficients, $i \in\{1,2, \ldots, p\}, v$ is the $N \times 1$ vector of intercepts, and the $\boldsymbol{\varepsilon}_{t}$ is the $N \times 1$ vector of white noise process, $E\left(\boldsymbol{\varepsilon}_{t}\right)=\mathbf{0}, E\left(\boldsymbol{\varepsilon}_{t} \boldsymbol{\varepsilon}_{t}{ }^{\prime}\right)=\Sigma_{\varepsilon}<\infty$, and for $t \neq s E\left(\boldsymbol{\varepsilon}_{t}\right.$ $\left.\varepsilon_{s}{ }^{\prime}\right)=0$. The $\operatorname{VAR}(p)$ model can be written in a $\operatorname{VAR}(1)$ form as $Y_{t}=V+A Y_{t-1}+e_{t}$,

where $Y_{t}=\left(\begin{array}{llll}y_{t} & y_{t-1} & \ldots & y_{t-p}\end{array}\right)^{\prime}, V=\left(\begin{array}{llll}v & 0 & \ldots & 0\end{array}\right)^{\prime}, A=\left[\begin{array}{ccccc}A_{1} & A_{2} & \cdots & A_{p-1} & A_{p} \\ I_{N} & 0 & \cdots & 0 & 0 \\ 0 & I_{N} & & \vdots & \vdots \\ \vdots & & \ddots & \vdots & \vdots \\ 0 & 0 & \cdots & I_{N} & 0\end{array}\right], e_{t}=$ $\left(\begin{array}{llll}\varepsilon_{t} & 0 & \ldots & 0\end{array}\right)^{\prime}$. In order to estimate the impulse response functions (IRFs) and the 
forecast error variance decompositions (FEVDs), the VAR model is rewritten into the $\mathrm{MA}(\infty)$ representation as follows:

$$
Y_{t}=\mu+\sum_{i=0}^{\infty} A^{i} e_{t}=\left(I_{N}-A L\right)^{-1} V+\Phi_{i}(L) e_{t}
$$

where $L$ is the lag operator, $L^{j} Y_{t}=Y_{t-j}, j \in \mathbb{R}, \Phi(L)$ being the polynomial such that $\Phi_{i}(L)$ $=J A^{i} J, J=\left(\begin{array}{lll}I_{N} & 0 \ldots 0\end{array}\right)$. Elements in $\Phi_{i}(L)$ are the impulse responses, i.e., $\phi_{j k, i}$ is the reaction of variable $j$ to the shock in variable $k$ in period $i$. In practice, the elements in $e_{t}$ are correlated, so the assumption $t \neq s E\left(\varepsilon_{t} \varepsilon_{s}{ }^{\prime}\right)=0$ does not hold. One approach is to observe the Cholesky decomposition of the variance-covariance matrix of the error term. Another one is to observe generalized IRFs and FEVDs, which does not rely on the ordering of the variables such as the Cholesky one. GIRFs are based on mean responses by integrating out other shocks, as defined by Pesaran and Shin (1998):

$$
G I_{y}\left(h, \delta_{j}, I_{t-1}\right)=E\left(\mathrm{Y}_{t+h} \mid e_{j t}=\delta_{j}, I_{t-1}\right)-E\left(\mathrm{Y}_{t+h} \mid I_{t-1}\right)
$$

where $\delta_{j}$ is the shock given to element $j$ in $e_{t}, I_{t-1}$ is the information set, $h$ is the horizon of the ahead forecast, and with the assumption of normal distribution of error terms, it follows that (Koop, Pesaran and Potter, 1996):

$$
E\left(e_{t} \mid e_{j t}=\delta_{j}\right)=\left(\sigma_{1 j} \sigma_{2 j} \ldots \sigma_{N j}\right)^{\prime} \sigma_{j j}^{-1} \delta_{j}=\sum_{\varepsilon} u_{j} \sigma_{j j}^{-1} \delta_{j}
$$

with $u_{j}$ being a $N \times 1$ vector of zeros with exception of value 1 in place $j$, so that the unscaled GIRFs of the $j$-th variable is estimated as the expression $\frac{\Phi_{h} \sum_{\varepsilon} u_{j}}{\sqrt{\sigma_{j j}}} \frac{\delta_{j}}{\sqrt{\sigma_{j j}}}$. Setting $\delta_{j}=\sqrt{\sigma_{j j}}$, the scaled GIRF of variable $j$ at horizon $h$ is equal to

$$
\psi_{j}(h)=\sigma_{j j}^{-1 / 2} \Phi_{h} \sum_{\varepsilon} u_{j},
$$

and is the effect of one standard error shock to the equation $j$ at time $t$ on expected values of $Y_{t}$ at $t+h$. Now, the GIRFs from (4) are used to construct the GFEVDs, i.e., the proportions of the $h$-step ahead FEVDs of variables $j$ due to shocks in variables $k$ in the model:

$$
\theta_{j k}(h)=\frac{\sigma_{j j}^{-1 / 2} \sum_{i=0}^{h-1}\left(u_{j}^{\prime} \Phi_{i} \sum_{\varepsilon} u_{k}\right)^{2}}{u_{j}^{\prime} \Phi_{i} \sum_{\varepsilon} \Phi_{i}^{\prime} u_{k}} .
$$

The next step is the construction of the spillover index of Diebold and Yilmaz (2009, 2012). In the 2009 paper, the Cholesky decomposition was applied in the IRF and FEVD estimation, but the paper from 2012 utilizes the GFEVDs in (5). The values $\theta_{j k}(h)$ are normalized as follows:

$$
\tilde{\theta}_{j k}(h)=\frac{\theta_{j k}(h)}{\sum_{k=1}^{N} \theta_{j k}(h)}
$$


and the total spillover index is calculated based on the cross-variance shares defined in (6):

$$
S(h)=\frac{\sum_{\substack{j, k=1 \\ j \neq k}}^{N} \tilde{\theta}_{j k}(h)}{N} 100 \%
$$

and measures the contribution of spillovers in all variables to the total forecast error variance. By taking the GFEVD approach, the directional and net spillover indices can be estimated as well. The spillover which a variable $j$ receives from other variables $k$ is calculated as

$$
S_{j} \times(h)=\frac{\sum_{\substack{k=1 \\ j \neq k}}^{N} \tilde{\theta}_{j k}(h)}{N} 100 \%
$$

and the spillover of shocks from variable $j$ to other variables $k$ as

$$
S \times_{j}(h)=\frac{\sum_{\substack{k=1 \\ j \neq k}}^{N} \tilde{\theta}_{k j}(h)}{N} 100 \% .
$$

The net indices can be estimated as well, as the total net index for every variable in the model, by subtracting (9) from (8), and pair-wise indices (between two variables, similar to the indices in (8) and (9)) can be estimated in order to compare two variables, alongside the net pair-wise indices. In order to include the dynamics in the analysis, the $\operatorname{VAR}(p)$ model and all of the needed spillover indices will be estimated on a rolling-window basis. Most of the spillover-indices literature utilizes this approach as greater insights from the dynamic analysis can be obtained (see Dumitrescu, 2015; Yarovaya, Brzeszczyński and Lau, 2016; Škrinjarić and Šego, 2019; Gross and Siklos, 2019).

\section{EMPIRICAL RESULTS}

\subsection{DATA SELECTION AND DESCRIPTION}

For the purposes of the empirical analysis, monthly data on the industrial production index (IIP, $2015=100)$ and the harmonized index of consumer prices (HICP, $2015=100)$ were collected from the Eurostat (2021) database; data on nominal bank loans to the private sector (LN, in billions of euro) from the Deutsche Bundesbank (DBE, 2021) database; the 3-month Euribor rate (IRATE) and the German CISS were collected from ECB (2021) statistical data warehouse.

CISS (Composite Indicator of Systemic Stress) was introduced in Hollo, Kremer and Lo Duca (2012), and it measures the state of the systemic financial instability in the euro area. There are two main reasons why this paper uses the CISS indicator. First, as explained in Hollo, Kremer and Lo Duca (2012), this variable covers the main 
channels of financial instability sources: the financial intermediaries, money, bond, equity, and foreign exchange markets. Secondly, this measure has been extensively used in the past literature, which indicates that it is reliable (e.g., Senapati and Kavediya, 2020; Jin and Nadal de Simone, 2020; Dufour, Marra and Sangiorgi, 2019; Bucacos, 2018; Guidolin and Pedio, 2017; Zhagini, 2016; Delatte, Fouquau and Portes, 2014; Mittnik and Semmler, 2013; etc.). As Hartmann et al. (2015) emphasize, the CISS variable is particularly important for those economies with bank-centric financial systems ${ }^{2}$. By utilizing CISS as the measure of systemic stress, as Hollo, Kremer and Lo Duca (2012) and Huotari (2015) note, we observe the systemic stress as the materialization of risks that cause financial instability. These variables are utilized in Hartmann et al. (2015), van Roye (2011) for Germany in particular ${ }^{3}$, and similar ones in Kremer (2015), Borys, Horváth and Franta (2009), Duprey and Ueberfeldt (2020), Martins (2020), and Havránek, Horváth and Matějů (2012). The core variables were calculated as in Kremer (2015): the annual log differences of the $\mathrm{HICP}^{4}$, annual log differences of the IIP index ${ }^{5}$; and the ERATE is the measure of the conventional monetary policy rate. Finally, the year-on-year growth in the LN (bank loans) is used, as Hartmann et al. (2015) explain that bank lending had a great role in previous financial crises. The original data ranges from January 1999 to December 2020, and the year-on-year growth rates start in January $2000^{6}$. The CISS variable as an overall measure of the financial instability is used in the original form. All variables were checked for stationarity, and where needed, variables were transformed to be stationary ${ }^{7}$, so that the standard errors and the derived test statistics can be used.

For the robustness checking of the results, the CISS variable was transformed via the positive square root of the original values, as in Kremer (2015). All of the estimations were re-done with the transformed CISS variable (SQCISS). This was done so that potential nonlinearities within the original form of the variable can be controlled for. As a final checking of the robustness, the quarterly seasonally adjusted GDP, collected from the Eurostat (2021) database was be transformed via the Chow-Lin (1971) interpolation procedure ${ }^{8}$ to the monthly frequency. The monthly IIP data were used to construct monthly GDP, as in Boeckx, Dossche and Peersman (2014), as well as the monthly index of deflated turnover in retail sale

\footnotetext{
${ }^{2}$ The CISS indicator is chosen for the analysis, as it covers the main channels of financial instability sources: financial intermediaries, money, bond, equity, and foreign exchange markets. The rolling correlations between these five sources in terms of their relevant variables and the CISS value are given in figure A4 in the appendix. It can be seen that this variable captures the dynamics on the relevant markets quite well, due to great values of bivariate correlation coefficients.

${ }^{3}$ With the exception of own systemic stress variable construction.

${ }^{4}$ To measure year-on-year inflation rate (as an aggregate price level changes measure).

${ }^{5}$ Aggregate economic activity changes to measure year-on-year IIP growth (as in Kremer and Chavleishili, 2021, it measures the cyclical component of the IIP).

${ }^{6}$ Thus, the total number of observations for each variable is 252 . Where needed, the seasonal adjustment of the original data was made so that no seasonality remained.

${ }^{7}$ The only non-stationary variable was the interest rate, which was confirmed via Augmented Dickey-Fuller and the KPSS tests. Thus, the year-on-year difference of the interest rate was calculated. Please see table A1 in the appendix.

${ }^{8}$ More details on this interpolation procedure can be found in Sax and Steiner (2013) or Marini (2016). This procedure has been found to be good in converting the GDP series from quarterly to monthly, see Mönch and Uhlig (2005) or Hoven and Scherus (2013).
} 
(seasonally adjusted, $2015=100$, Eurostat, 2021) as in Chamberlin (2010) and Frale et al. (2008). In the first step, the monthly data are estimated for the level values, and in the second the year on year growth rates are calculated. The abbreviations and description of each variable are given in table 1.

\section{TABLE 1}

Variables description

\begin{tabular}{|c|c|}
\hline Abbreviation & Full name \\
\hline DIIP & Year-on-year growth rate of index of industrial production \\
\hline DHICP & Year-on-year growth rate of harmonized index of consumer prices \\
\hline DIRATE & Year-on-year change of the 3-month Euribor rate \\
\hline DLN & Year-on-year growth rate of nominal bank loans to the private sector \\
\hline CISS & German Composite Indicator of Systemic Stress \\
\hline SQ_CISS & Square root of CISS \\
\hline DGDP & Year-on-year growth rate of gross domestic product \\
\hline
\end{tabular}

Source: Eurostat (2021), DBE (2021), ECB (2021).

\subsection{MAIN RESULTS}

A static approach was made first, where the VAR model was estimated over the entire dataset, with a lag length of $p=2$, based on the information criteria. For the entire sample, the Spillover table was estimated for $h=12$, and is shown in table 2. The main interpretations are as follows. If we focus on the first row, the values indicate how much of the variance of variable DIIP is explained by the shocks in all other variables: $52.84 \%$ due to shocks in the same variable, $5.05 \%$ due to shocks in DHICP, etc. The column entitled "From" indicates the average spillover index value variance of a variable has received from shocks in other variables in the model. For example, the variance of DIIP is, on average, explained by shocks in four other variables in the system in the amount of $11.79 \%$. Similarly, "T_from" includes the sum of all spillovers from other variables to the variance of every variable. The row titled "To" is the average spillover of shocks in a variable in each column that explains variances of other variables. Value 9.15 is the average percentage explained of the variances of other variables in the model, due to shocks in variable DIIP. Again, something similar is true for the row "T_to": it contains the sum of spillovers of shocks in each variable to all other variables in the model.

TABLE 2

Spillover table, full sample, in percent

\begin{tabular}{|c|c|c|c|c|c|c|c|}
\hline Variable & DIIP & DHICP & DIRATE & DLN & CISS & From & $T$ from \\
\hline DIIP & 52.84 & 5.05 & 16.77 & 1.89 & 23.46 & 11.79 & 47.17 \\
\hline DHICP & 21.15 & 63.80 & 2.29 & 0.66 & 12.09 & 9.05 & 36.19 \\
\hline DIRATE & 12.35 & 1.27 & 56.89 & 1.17 & 28.32 & 10.77 & 43.11 \\
\hline DLN & 0.07 & 1.38 & 9.61 & 84.55 & 4.38 & 3.86 & 15.44 \\
\hline CISS & 3.03 & 4.25 & 2.21 & 0.45 & 90.06 & 2.49 & 9.94 \\
\hline To & 9.15 & 2.99 & 7.72 & 1.04 & 17.06 & - & - \\
\hline $\mathrm{T}$ to & 36.60 & 11.95 & 30.88 & 4.17 & 68.25 & - & 37.96 \\
\hline
\end{tabular}

Source: Author's calculation. 
Finally, the total spillover index value is given in the last cell of table 2, and it is equal to $37.96 \%$. Thus, over the entire observed period, a moderate value of the spillover indices is observed. By focusing on the column CISS, it is seen that shocks in the systemic risk spill over to other variables in relatively great amounts, especially regarding the DIRATE and DIIP (28.32\% and $23.45 \%$, respectively). This is according to the previous static analysis in van Roye (2011) for Germany, where the IRFs indicated the greatest reaction of the two mentioned variables to shocks in the financial stability variable. On the other side, the CISS variance is explained by shocks in other variables in a very small manner (row regarding variable CISS). These results indicate that the shocks that occur in variable CISS have great effects on the selected variables, i.e., financial instability shocks affect the economy in the observed sample. Previous findings from the euro area also show that the IRF functions of these variables have the greatest reactions to CISS shocks in Kremer (2015).

\section{Figure 1}

Total spillover index, $h=12$, rolling windows 30, 36 and 42 months

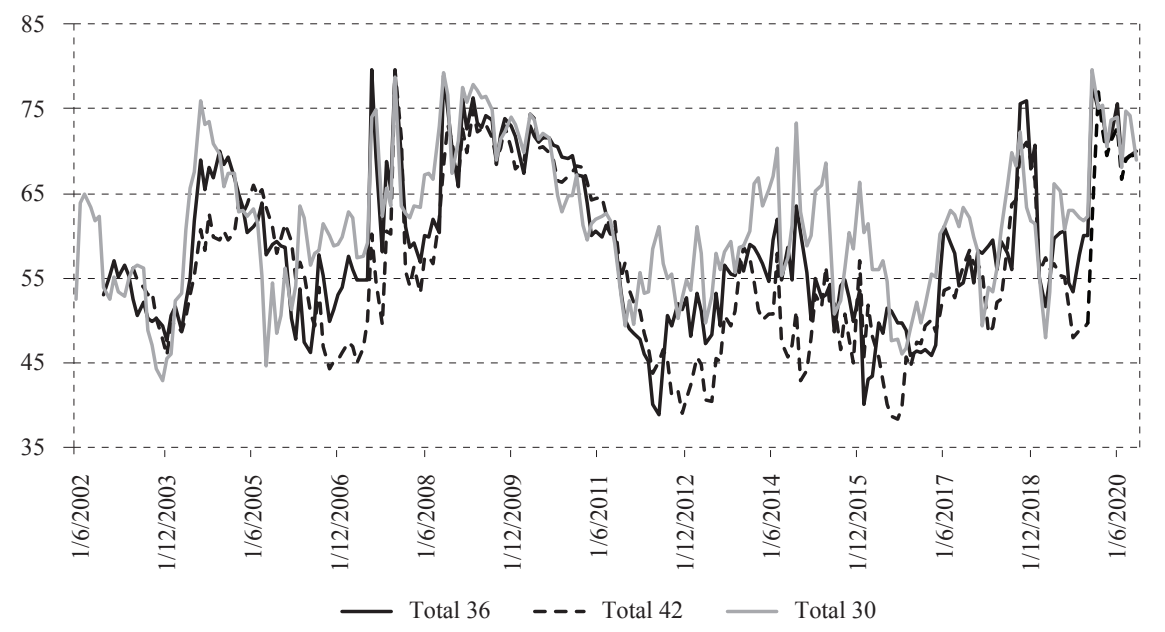

Source: Author's calculation.

However, these are static results. That is why the next step was taken, in which the dynamic VAR model and spillover tables have been estimated. In that way, information on which variable is the net receiver or emitter of shocks in the economy is obtained. Previous research focuses on the IRFs and the FEVDs statically. However, such an approach did not give insights into the direction of the shocks and their changes over time. The rolling window approach used the length of 30, 36, and 42 months. The 36 month length was chosen so that a full 3 -year period is included for the estimation part, and the 30 and 42 month lengths were utilized so that a robustness check could be performed in the subsequent section (as in Diebold and Yilmaz, 2009; 2012). Firstly, we comment on the 36 month window length results until the robustness checking. The overall values of the rolling spillover index indicate changing dynamics over time. This is seen especially during the problem of insolvency of WorldCom in 2002 (van Roye, 2014), the financial crisis 
of 2007-2008 when all spillovers increased, and again the increases are visible during the sovereign debt crisis which was at its highest in 2012. The increase of the spillovers is visible in the latest crisis, COVID-19, at the beginning of 2020 as well. However, the values of the total spillover increased during the financial crisis for a longer period than in the COVID-19 crisis. This is in line with the current belief that the pandemic crisis is a short-term negative shock (as suggested in Boivin, Giannoni and Stevanović, 2020), due to the quicker reaction of governments and central banks (Ehnts and Paetz, 2021), with banks being part of the solution and not the problem (Giese and Haldane, 2020) in the COVID-19 case.

The total spillover index only gives insight into the overall spillover among all of the variables. If we want to focus on the spillovers of systemic stress to other variables, the pair-wise and the net pair-wise indices need to be observed as well. This is done in figure $2^{9}$, which observes the net spillovers between each variable and the CISS. When the value of the spillover index is positive, it means that the variable is a net receiver of shocks from CISS. Otherwise, the CISS is the receiver of shocks from the selected variable. First, the interchanges of being the net receiver or net giver of shocks change over time for variables. This is in line with previous research that observes disproportional effects between the systemic stress and macroeconomic variables, in terms of size or signs (Li and St-Amant, 2010; Fry-McKibbin and Zheng, 2016). This provides the macroprudential policymakers with more detailed insights into the sources of when systemic stress is the net emitter or receiver of shocks to the rest of the economy. The DIRATE (lower left panel of figure 2) is the net receiver of shocks in systemic stress the majority of the time. This is in line with conventional views of reactions of monetary policy to the financial instability (Bernanke and Gertler, 2001; or Bean et al., 2010). Furthermore, as the central banks have such reactions to the increased systemic stress, the CISS variable in this case provides a good predictor of future interest rate movements. This is because the values of the spillover index, in this case, are high. Next, by observing the pair-wise spillovers between CISS and DIIP (upper left panel of figure 2), the magnitude of the spillovers is greatest during the crisis periods. Otherwise, the values are close to zero, i.e., the spillovers are close to insignificant. This is in line with the non-responsiveness of the real economic growth to the financial instability shocks in tranquil times found in Hakkio and Keeton (2009), Hubrich and Tetlow (2014), van Roye (2011), as well as Hollo, Kremer and Lo Duca (2012). The dynamics of the net spillover for the DHICP case (upper right panel, figure 2) that the effects of the inflation stabilization before the financial crisis have contributed to the CISS variability, as the latter variable was the net receiver of shocks in DHICP. This is in line with Frankel (2012), where the author comments on the problems of focusing mostly on inflation targeting before the 2007-2008 financial crisis. This changed in the stabilization period after the crisis. Finally, the DLOAN results (right bottom panel, figure

\footnotetext{
${ }^{9}$ Figure 2 depicts results for 36 month rolling windows, whereas the robustness of the results in terms of 30 and 42 month rolling windows are shown in figure.
} 
2) indicate that the values of the spillovers increase when the loan growth rate increases, which in return increases the CISS values. This is in line with findings in Mallick and Sousa (2013), where the authors observe that rapid credit expansions raise financial imbalances. The interchanges of net emitting or receiving of shocks between DLOAN and CISS after the financial crisis is also in line with the previous research. As the banks were de-risking their balance sheets regarding bad credits, the policies regarding credit channels were not much effective. Then, when the credit growth started to increase (period 2013-2018), the DLOAN became the net emitter of shocks to CISS. This is in line with Jordá, Schularick and Taylor (2011), and Schularick and Taylor (2012), in which the findings indicate that credit growth is the best predictor of financial instability.

\section{Figure 2}

Net pair-wise spillover indices between each variable and CISS, $h=12$, rolling windows 36 months
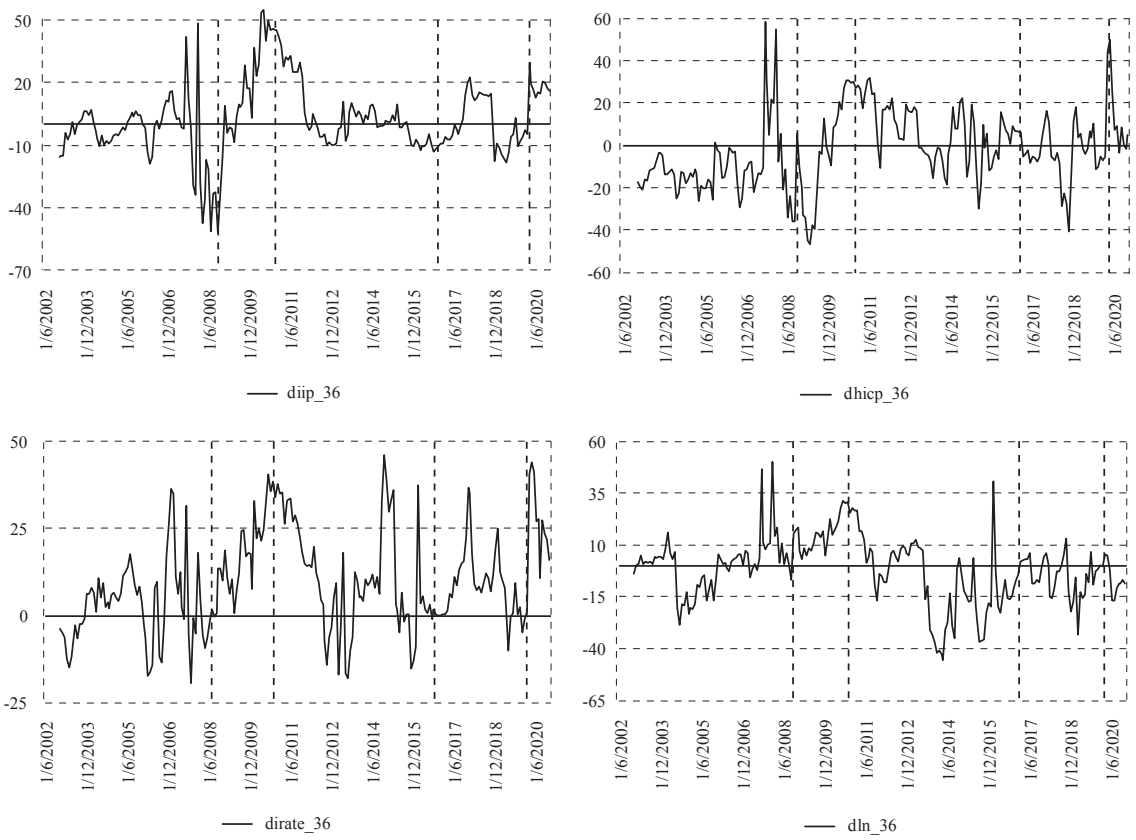

Note: Dashed lines indicate dates from left to right: Global financial crisis, Euro crisis, Brexit referendum vote and COVID-19 crisis.

Source: Author's calculation.

As previous research divides the analysis into good or bad states, i.e., regimes of business cycles, different systemic stress regimes, etc., rolling Granger test results between CISS and each variable in the system was observed as well. Thus, the null hypothesis assumes no causality from variable $x$ to $y$ within the the VAR model. The results are given in figure 3 where CISS is the cause, and figure 4 shows the CISS as the response variable. This enables better information on when the shocks in one variable have significant spillovers to the other. First, the results are in line 
with Cardarelli, Elekdag and Lall (2011), who also find that systemic stress is not always the preceding variable in the model. This is true in this research as well, as the $p$-value results of the Granger tests interchange in terms of (non)rejection of the null hypothesis. Some of the main findings are as follows. The CISS variable does not cause DIIP as well as other variables in tranquil times, as found in Hartmann et al. (2015), who explain this via the fact that CISS should be measuring the systemic stress and not general financing conditions. Next, the result concerning when the DLN variable emits shocks to CISS is significant in figure 4 (lower right panel) is in line with that of Misina and Tkacz (2008). The aforementioned problems of inflation targeting before the financial crisis are found to be statistically significant in the upper right panel of figure 4. These findings are in line with CEPR (2013); and the significance of shocks in DHICP that spillover to CISS is found to be mostly during the low systemic stress periods, as in Li and St-Amant (2010). Finally, as the Granger test results vary over time, which means that the shocks in CISS are not the ones that are driving the movement of the rest of the variables. Rather, CISS is a good variable to capture shocks in other variables in the model (figure 3 ) as a realization of financial risk during the crisis periods.

\section{Figure 3}

Comparison of rolling net spillover indices (grey lines, right axis) to the Granger causality test p-value (black lines, left axis), 36 months window length, CISS is the cause
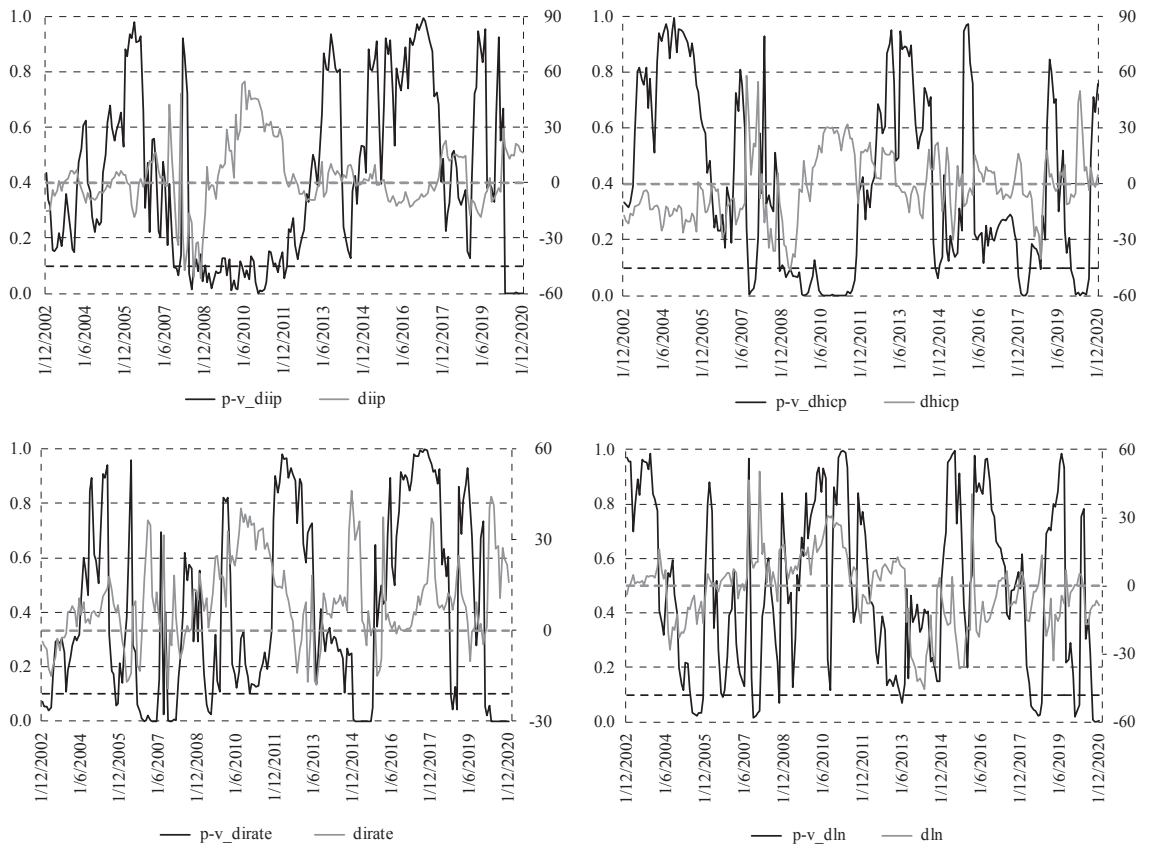

Note: Dashed grey line is the zero value for the spillover index; black dashed line is the 10\% significance level.

Source: Author's calculation. 
In general, the results obtained here support previous findings that focus on asymmetric models where the business cycle and/or systemic stress threshold values govern the sign and magnitude of the reactions to shocks within the system. This is visible in the changes in the dynamics of being a net receiver or emitter of shocks between the pairs of selected variables and CISS. Periods of high systemic stress and economic downturns generate greater overall spillover effects between the variables, compared to the tranquil times. These results corroborate previous findings in similar research, such as Mittnik and Semler (2013). These authors find that the reactions to the shocks in systemic stress or macroeconomic variables depend on the sign and size of the shocks. Although there is evidence here that the systemic stress shocks have a great role in macroeconomic fluctuations, as in Christiano, Motto and Rostagno (2010), Del Negro et al. (2017), and Jermann and Quadrini (2012); the rolling Granger test results indicate that a feedback relationship exists. Thus, the analysis and decision-making should be based on the interchanges of the predictive power of the observed variables in the model.

\section{Figure 4}

Comparison of rolling net spillover indices (grey lines, right axis) to the Granger causality test p-value (black lines, left axis), 36 months window length, CISS is the response
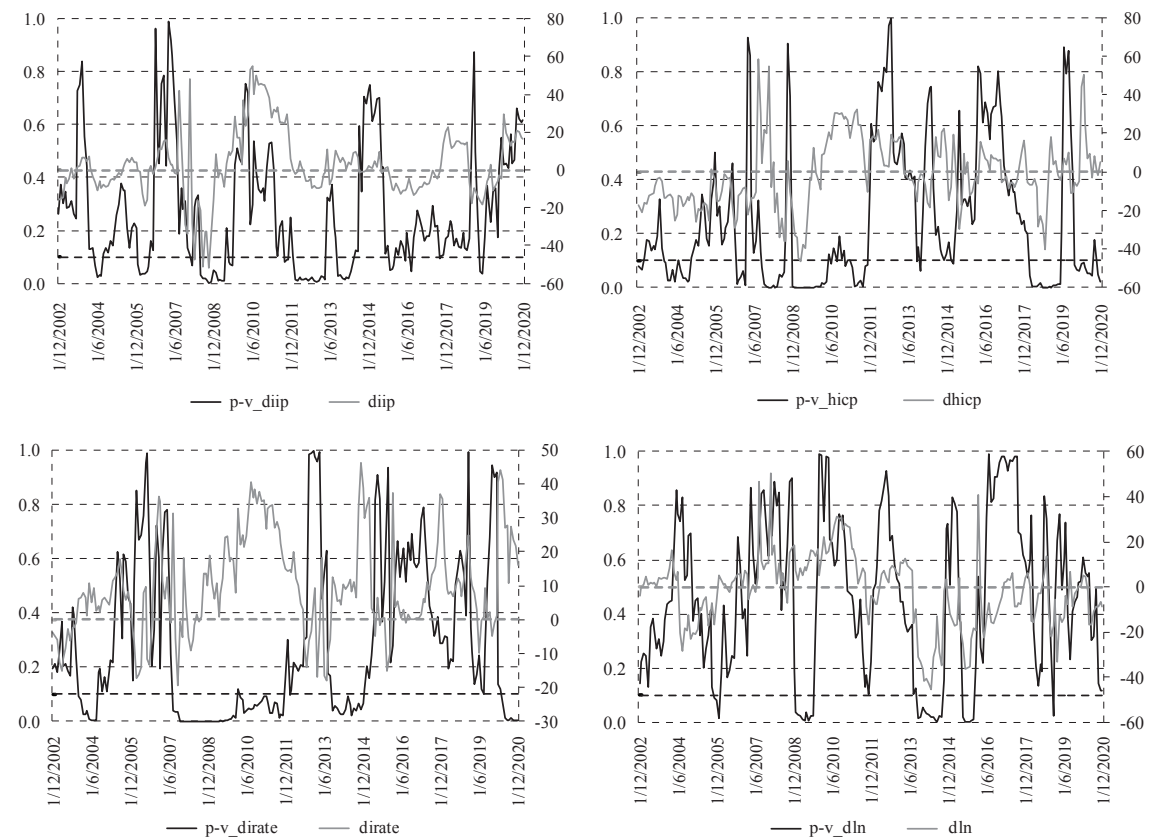

Note: Dashed grey line is the zero value for the spillover index; black dashed line is the $10 \%$ significance level.

Source: Author's calculation.

To summarize, it can be stated that the German central bank, since losing its monetary policy power since 1999, was more of a reactor to changes in the economy, 
due to its usual cuts in interest rates after the GFC. This is seen in interest rates being the net receiver of shocks in crises times in figure 2. It is expected that similar behaviour can be found in the future. The opposite is true for credit demand: during periods of economic tranquillity, the CISS registers low values, and changes in this variable spill in a greater manner to the DLN variable (see the subperiod after the GFC when the economy recovered). As households and nonfinancial corporations were recovering, with rising sentiment, bank credits to the private economy were greatly under the influence of the subdued systemic stress. The pandemic was a different type of a shock to the economy, so it can be expected that bank loans will not be affected for very long by shocks in CISS values. It is already seen that by the end of 2020, the DLN had become a greater giver of shocks again. Inflationary pressures are continuing until the end of 2021, and are expected to continue until early next year (ECB, 2020). That is why it can be expected that after the initial shock at the beginning of 2020 in the pairwise spillover index, the trend will be reversed. This is due to inflation affecting financial markets movements, and consequently, the CISS value movements as well. After the GFC, as banks were getting rid of the bad credits, changes in bank balance sheets affected the policies regarding credit channels, which were not effective. The opposite is true in times of private loan recovery, as the CISS variable becomes the net receiver of shocks in DLN. This indicates that the changes of credit growth contribute to future financial instability in a great manner. The real economic activity (in terms of IIP or GDP) has its lowest spillover indices (closest to zero values) in times of no realized stress; it is known in the literature that financial stress affects the lower percentiles of GDP growth (the growing literature on growth-at-risk focuses on the lower tail of the GDP growth distribution).

Finally, the approach of this paper can be compared to the regime switching in Hartmann et al. (2015). Neither approach assumes the linear constant relationship between the variables, as a usual VAR model would. However, the regime switching approach assumes the existence of two or more regimes in which the interrelationship between the variables is different. However, one drawback of a regime switching approach is that the shifts between regimes are abrupt, i.e., the probabilities of being in a regime identify abrupt changes in the system. This is not a realistic assumption for macroeconomic variables, and especially those that have sluggish behaviour, such as bank credit. Regime switching is utilized on variables such as CISS, but when it is analyzed on a daily basis for portfolio management purposes, (i.e., how do abrupt changes in financial markets affect investors and other interested parties?). Thus, a better approach would be either some form of a smooth transition VAR, or an approach such as this one, in which a linear relationship exists, but the parameters of the model change over time due to the rolling estimation.

\subsection{ROBUSTNESS CHECKING}

To test the robustness of the results, several approaches were used. Firstly, the original VAR model was re-estimated with the rolling window lengths of 30 and 42 months, as already noted in the previous subsection. This follows the 
recommendations of Diebold and Yilmaz $(2009,2012)$, where the authors suggest changing the length of the rolling window estimation. The main idea is to obtain if the same dynamics occur in the spillover indices over time. By observing figures 1 and 5, the total and net spillover indices have the same dynamics over time regardless of the window estimation length. Of course, the longer the window length is, the more smoothed out the series becomes.

Next, the same procedure was re-done, i.e., the VAR model with the rolling spillover index was estimated by including the square root of the CISS variable, as suggested in Kremer (2015). Figure 6 contrasts the total spillover indices of the original variable and its squared root. Again, the dynamics are very similar over the entire observed period. The indices almost coincide the majority of the time. Another robustness checking was made by using the interpolated GDP values on a monthly basis. The model was re-estimated on the entire sample, and the spillover table is shown in table 3 . The changes are minor when compared to values in table 2, with the same conclusions as well. Furthermore, the dynamic analysis was re-done with the interpolated series as well. Figure 7 compares just the total spillover index values for the DGDP and DIIP for the rolling window length of 36 months and the series are almost perfectly aligned the majority of the time.

\section{Figure 5}

Net pair-wise spillover indices between each variable and CISS, $h=12$, rolling windows 30, 36 and 42months
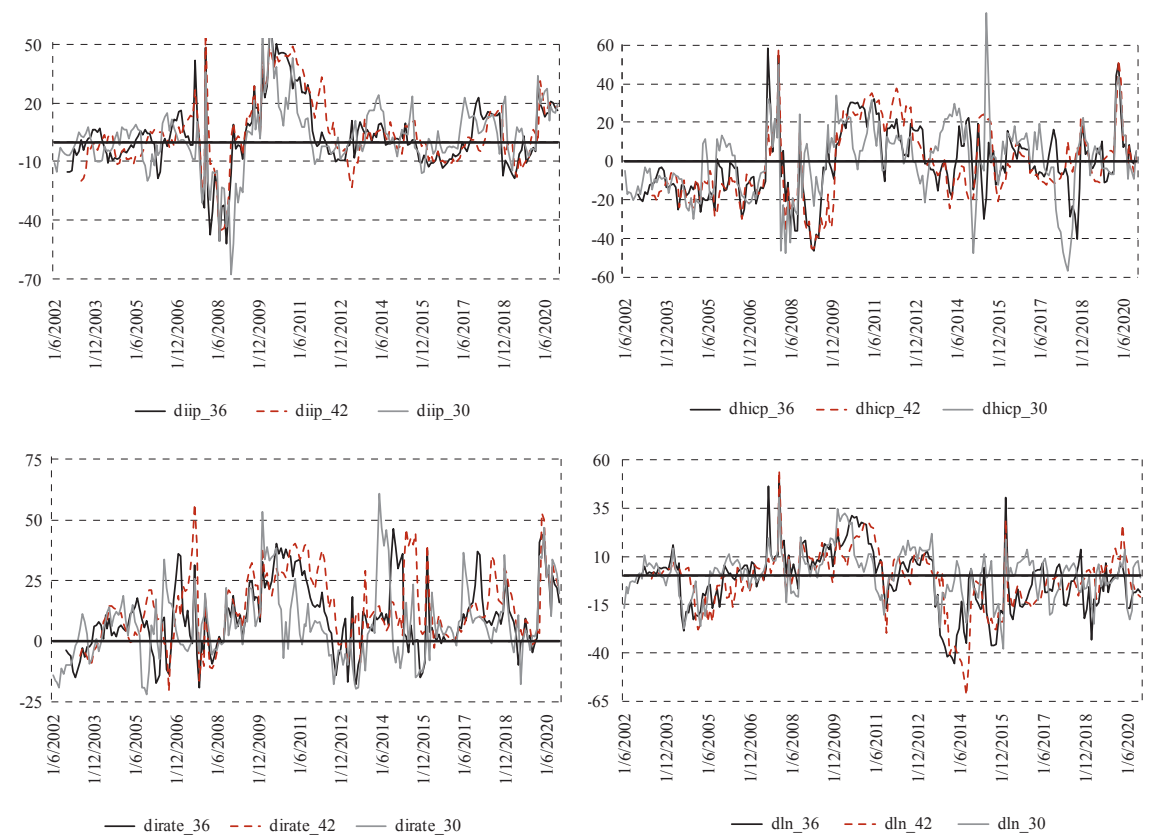

Source: Author's calculation. 
Next, more comparisons are included in the appendix. Figure A1 compares all three values of total spillover indices for DGDP and DIIP, for the 30, 36, and 42 window lengths; and figure A2 does the same, but for the pair-wise net spillover indices. Again, the dynamics in all series are the same. As Diebold and Yilmaz $(2009,2012)$ suggest to change the length of the forecast horizon $h$, the estimation of the rolling VAR model and the spillover indices was obtained for the original set of the variables (i.e., the DIIP one included in the analysis). However, the value for $h$ was chosen to be 18 and then 24 months. The pair-wise net spillover indices between each of the variables and CISS are compared in figure A3. It is visible that the lines are very close to one another, for all four pairs of variables.

Finally, additional checking was made to compare the results of this analysis to the SVAR (structural VAR) approach, in which additional assumptions can be made about the short-term effects of shocks in one variable to another. Kremer (2015) and other related literature in which SVARs are utilized in order to examine similar questions was followed. The following ordering of variables was done: DHICP, DIIP, CISS, DIRATE, DLN, in the setting of $A u_{t}=B \varepsilon_{t}$, where matrices $A$ and $B$ denote matrices of coefficient that need to be estimated, $u$ is the vector of residuals of the VAR model, and $\varepsilon$ is the vector of unobserved structural innovations. Firstly, the ordinary VAR model was estimated over the entire sample, GIRFs were extracted to see the effects of shocks in other variables in CISS reaction, and vice versa - CISS shocks reactions in other variables in the system. Secondly, the SVAR IRFs were estimated to compare the results. Figures A5 and A6 show both results that indicate that the dynamics of IRFs is the same. Thus, we are confident that the results and conclusions from them are robust.

\section{Figure 6}

Comparison of total spillover index, 36 rolling window length, CISS (total 36, black line) and squared root of CISS (sqciss, grey line) in VAR model

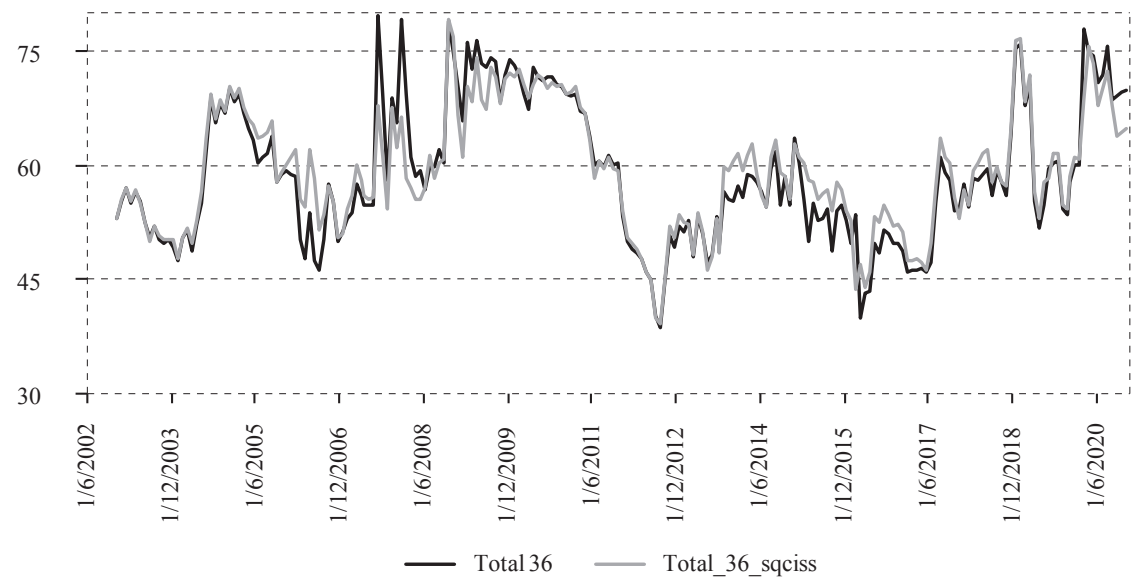

Source: Author's calculation. 
TABLE 3

Spillover table, full sample, in percent, monthly DGDP used

\begin{tabular}{|c|c|c|c|c|c|c|c|}
\hline Variable & DGDP & DHICP & DIRATE & DLN & CISS & From & T_from \\
\hline DGDP & 61.90 & 2.64 & 13.45 & 2.46 & 19.55 & 9.53 & 38.10 \\
\hline DHICP & 17.45 & 65.88 & 4.08 & 1.52 & 11.07 & 8.53 & 34.12 \\
\hline DIRATE & 8.92 & 1.15 & 62.84 & 0.56 & 26.52 & 9.29 & 37.15 \\
\hline DLN & 0.27 & 1.50 & 9.09 & 84.85 & 4.29 & 3.79 & 15.15 \\
\hline CISS & 3.55 & 5.26 & 2.01 & 0.59 & 88.59 & 2.85 & 11.41 \\
\hline To & 5.64 & 2.64 & 7.16 & 1.28 & 15.36 & - & - \\
\hline T_to & 30.19 & 10.55 & 28.63 & 5.13 & 61.43 & - & 33.98 \\
\hline
\end{tabular}

Source: Author's calculation.

\section{Figure 7}

Total spillover index, $h=12$, rolling window length 36 months, comparison of DIIP (grey line) to the DGDP (black line) variable specification

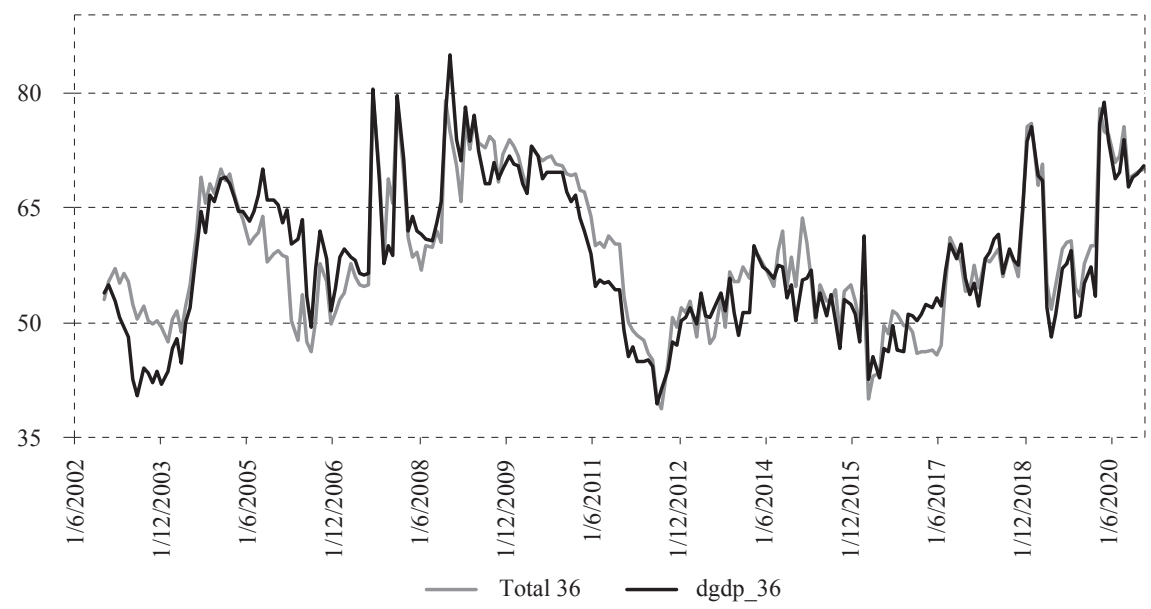

Source: Author's calculation.

\section{CONCLUSION}

Macroprudential policy is at the centre of attention nowadays again, due to the last crisis induced by the COVID-19 pandemic. The interaction between systemic risk and the real economy is still insufficiently explored. This is especially true regarding the assumptions of asymmetric relationships, nonlinearities, and dynamic changes in interrelationships between systemic stress and the rest of the economy. Using the approach of this research can provide the analysts and policy decisionmakers insights into the changing dynamics of the aforementioned issues. Results in this research have indicated that there are times when a net spillover between two variables is increasing or decreasing over time. If such a trend is observed, additional analysis can be made so that timely decisions and measures can be activated. Furthermore, as the macroprudential and monetary policymakers have to track the interrelationships between these variables over time, the approach in the study is straightforward and easy to interpret. As the timing and intensity of 
the specific measures are important, such an approach enables the policymakers to do so. Such an approach can be helpful in the ex-ante approach of macroprudential policy evaluation when the potential impacts of policy instruments have to be assessed before their activation. Such an approach is emphasized in Buch, Vogel and Weigert (2018).

Some of the shortfalls of this study were as follows. Using the CISS index as the overall measure of systemic stress could be problematic. Some previous research states some problems regarding this index during its construction, or concludes that the index is a stylized reduced-form of integrating financial instability into the economic modelling (Kremer, 2015). Thus, one cannot always deal with perfect variables. Next, one country was observed in the analysis. Although, previous findings indicate that majority of the results for selected European countries (either observing developed ones or, e.g., CEE markets) have similar conclusions. However, future work should analyse these dynamics for other countries, especially those that experience some specific macroeconomic problems. Regarding the latest COVID-19 crisis, the results indicate that the spillovers had a shorter period compared to the crisis of 2007-2008. However, at the time of conducting this research, data was available only until the end of 2020. Thus, although the government and the central bank have responded to this crisis faster than the previous one, the future spillovers are still uncertain. However, in 2019, the German central bank has activated the countercyclical capital buffer for the first time (Deutsche Bundesbank, 2019). This helped in the stabilization of the financial system. Furthermore, due to the European Central Bank purchasing securities on a large scale during the COVID-19 crisis, the banks have a lot of liquidity. Thus, the financing costs of the banks have barely risen, when compared to the aforementioned financial crisis (Buch, 2020).

As there are many other areas of research and methodological questions within the macroprudential policymaking, such as modelling networks, heterogeneity in different types of data, overall combining different ex-ante and ex-post analysis, future work should aim to utilize the results from analysis such as this one. This is due to not observing solely the sign and magnitudes of the impulse response functions as usually done in related research, but the overall changes in the dynamics of shock spillovers over time.

\section{Disclosure statement}

The author declares that there is no conflict of interest. 
1. Bean, C. [et al.], 2010. Monetary policy after the fall. Proceedings - Economic Policy Symposium. Jackson Hole, Federal Reserve Bank of Kansas City, pp. 267-328.

2. Bernanke, B. and Gertler, M., 1989. Agency costs, net worth, and business fluctuations. American Economic Review, 79(1), pp. 14-31.

3. Bernanke, B. and Gertler, M., 2001. Should central banks respond to movements in asset prices? American Economic Review, 91(2), pp. 253-257. https:// doi.org/doi:10.1257/aer.91.2.253

4. Bernanke, B., Gertler, M. and Gilchrist, S., 1999. The financial accelerator in a quantitative business cycle framework. In: J. B. Taylor and M. Woodford, eds. Handbook of Macroeconomics, 1(part C), pp. 1341-1393. https://doi.org/ doi:10.1016/s1574-0048(99)10034-x

5. Blanchard, O. J. and Quah, D., 1989. The Dynamic Effects of Aggregate Demand and Supply Disturbances. American Economic Review, 79(4), pp. 655-673. https://doi.org/doi:10.3386/w2737

6. Bloom, N., 2009. The Impact of Uncertainty Shocks. Econometrica, 77(3), pp. 623-685. https://doi.org/doi:10.3982/ecta6248

7. Boeckx, J., Dossche, M. and Peersman, G., 2014. Effectiveness and transmission of the ECB's balance sheet policies. National Bank of Belgium, Working Paper Research, No 275.

8. Boivin, J., Giannoni, M. and Stevanović, D., 2020. Dynamic effects of credit shocks in a datarich environment. Journal of Business \& Economic Statistics, 38(2), pp. 272-284. https://doi.org/doi:10.1080/07350015.2018.1497507

9. Borys, M. M., Horváth, R. and Franta, M., 2009. The Effects of Monetary Policy in the Czech Republic: An Empirical Study. Empirica, 36(4), pp. 419443. https://doi.org/doi:10.1007/s10663-009-9102-y

10. Brunnermeier, M. and Sannikov, Y., 2014. A macroeconomic model with a financial sector. American Economic Review, 104(2), pp. 379-421. https://doi. org/doi:10.1257/aer.104.2.379

11. Brunnermeier, M., Eisenbach, T. M. and Sannikov, Y., 2012. Macroeconomics with financial frictions: a survey. NBER Working paper, No. 18102. https://doi. org/doi:10.3386/w18102

12. Bucacos, E., 2018. Financial Conditions and Monetary Policy in Uruguay: An MS-VAR Approach. IDB Publications Working Papers, No. 8275.

13. Buch, C., 2020. The Deutsche Bundesbank's 2020 Financial Stability Review.

14. Buch, C., Vogel, E. and Weigert, B., 2018. Evaluating macroprudential policies. European Systemic Risk Board. ESRB Working paper series, No 76.

15. Cardarelli, R., Elekdag, S. and Lall, S., 2011. Financial stress and economic contractions. Journal of Financial Stability, 7(2), pp. 78-97. https://doi.org/ doi:10.1016/j.jfs.2010.01.005

16. Chamberlin, G., 2010. Methods Explained: Temporal disaggregation. Economic \& Labour Market Review, 4, pp. 106-121. https://doi.org/doi:10.1057/ elmr.2010.157 
17. Chavleishvili, S. and Manganelli, S., 2019. Forecasting and stress testing with quantile vector autoregression. ECB Working Paper, No. 2330. Frankfurt am Main: European Central Bank.

18. Chow, G. C. and Lin, A. L., 1971. Best linear unbiased interpolation, distribution, and extrapolation of time series by related series. The Review of Economics and Statistics, 53(4), pp. 372-375. https://doi.org/doi:10.2307/1928739

19. Christiano, L. and Ikeda, D., 2011. Government policy, credit markets and economic activity. NBER working papers, No. 17142. https://doi.org/doi:10. 3386/w17142

20. Christiano, L., Eichenbaum, J. and Evans, C., 1996. The Effects of Monetary Policy Shocks: Evidence from the Flow of Funds. Review of Economics and Statistics, 78(1), pp. 6-34. https://doi.org/doi:10.2307/2109845

21. Christiano, L., Eichenbaum, M. and Evans, C. L., 1999. Monetary Policy Shocks: What Have we Learned and to What End? In: J. B. Taylor and M. Woodford, eds. Handbook of Macroeconomics, 1(part A), pp. 65-148. https:// doi.org/doi:10.1016/s1574-0048(99)01005-8

22. Christiano, L., Motto, R. and Rostagno, M. 2010. Financial factors in economic fluctuations. ECB Working papers, No. 1192.

23. Davino, C., Furno, M. and Vistocco, D., 2014. Quantile Regression - Theory and Applications. UK: John Wiley \& Sons.

24. DBE, 2021. DBE 2021 database.

25. Del Negro, M. [et al.], 2017. The Great Escape? A Quantitative Evaluation of the Fed's Non-Standard Policies. American Economic Review, 107(3), pp. 824-857. https://doi.org/doi:10.1257/aer.20121660

26. Delatte, A-L., Fouquau, J. and Portes, R., 2014. Nonlinearities in Sovereign Risk Pricing: The Role of CDS Index Contracts. NBER Working Papers, No. 19985. https://doi.org/doi:10.3386/w19985

27. Delli Gatti, D. [et al.], 2012. Mobility constraints, productivity trends, and extended crises. Journal of Economic Behavior and Organization, 83(3), pp. 375-393. https://doi.org/doi:10.1016/j.jebo.2012.03.011

28. Deutsche Bundesbank, 2019. Financial Stability Review 2019. Frankfurt am Main: Deutsche Bundesbank.

29. Diebold, F. X. and Yilmaz, K., 2009. Measuring Financial Asset Return and Volatility Spillovers with Application to Global Equity Markets. The Economic Journal, 119(534), pp. 158-171. https://doi.org/doi:10.1111/j.1468-02 97.2008.02208.x

30. Diebold, F. X. and Yilmaz, K., 2012. Better to Give than to Receive: Predictive Directional Measurement of Volatility Spillovers. International Journal of Forecasting, 28(1), pp. 57-66. https://doi.org/doi:10.1016/j.ijforecast.2011.02.006

31. Dufour, A., Marra, M. and Sangiorgi, I., 2019. Determinants of intraday dynamics and collateral selection in centrally cleared and bilateral repos. Journal of Banking \& Finance, 107(c), 105610. https://doi.org/doi:10.1016/j. jbankfin.2019.105610 
32. Dumitrescu, S., 2015. European Equity Market Return, Volatility and Liquidity Spillover Dynamics during the Eurozone Debt Crisis. Financial Studies, 19(2), pp. 30-50.

33. Duprey, T. and Ueberfeldt, A., 2020. Managing GDP tail risk. Otawa: Bank of Canada.

34. ECB, 2020. Economic bulletin, Issue 6. Frankfurt am Main: European Central Bank.

35. ECB, 2021. ECB Database. Frankfurt am Main: European Central Bank.

36. Ehnts, D. and Paetz, M., 2021. COVID-19 and its economic consequences for the Euro Area. Eurasian Economic Review, 11, pp. 227-249. https://doi.org/ doi:10.1007/s40822-020-00159-w

37. Engle, R. F. and Manganelli, S., 2004. CAViaR: Conditional autoregressive value at risk by regression quantiles. Journal of Business and Economic Statistics, 22(4), pp. 367- 381. https://doi.org/doi:10.1198/073500104000000370

38. Eurostat, 2021. Database.

39. Fisher, I., 1933. The Debt-Deflation Theory of Great Depressions. Econometrica, 1(4), pp. 337-357. https://doi.org/doi:10.2307/1907327

40. Frale, C. [et al.], 2008. A Monthly Indicator of the Euro Area GDP. EUI Working Paper, No. 2008/32.

41. Frankel, J., 2012. The death of inflation targeting. VoxEU, June 19, 2012.

42. Fry-Mckibbin, R. and Zheng, J., 2016. Effects of the US monetary policy shocks during financial crises - a threshold vector autoregression approach. Applied Economics, 48(59), pp. 5802-5823. https://doi.org/doi:10.1080/0003 6846.2016.1186792

43. FSB, 2020. Peer Review of Germany, Review Report. Financial Stability Board.

44. Galán, J. E., 2020. The benefits are at the tail: uncovering the impact of macroprudential policy on growth-at-risk. Journal of Financial Stability, 100831. https://doi.org/doi:10.1016/j.jfs.2020.100831

45. Giese, J. and Haldane, A., 2020. COVID-19 and the financial system: a tale of two crises. Oxford Review of Economic Policy, 36(S1), pp. S200-S214. https:// doi.org/doi:10.1093/oxrep/graa035

46. Giglio, S., Bryan, K. and Pruitt, S., 2016. Systemic Risk and the Macroeconomy: An Empirical Evaluation. Journal of Financial Economics, 119(3), pp. 457-471. https://doi.org/doi:10.1016/j.jfineco.2016.01.010

47. Granger, C. W., 2003. Time series concepts for conditional distributions. Oxford Bulletin of Economics and Statistics, 65(s1), pp. 689-701. https://doi. org/doi:10.1046/j.0305-9049.2003.00094.x

48. Gross, C. and Siklos, P., 2019. Analyzing credit risk transmission to the non-financial sector in Europe: a network approach. ESRB Working paper series, No 78.

49. Guidolin, M. and Pedio, M., 2017. Identifying and measuring the contagion channels at work in the European financial crises. Journal of International Financial Markets, Institutions and Money, 48(C), pp. 117-134. https://doi. org/doi:10.1016/j.intfin.2017.01.001 
50. Hakkio, S. C. and Keeton, W. R., 2009. Financial Stress: What Is It, How Can It be Measured, and Why Does It Matter? Economic Review, 94(2), pp. 5-50.

51. Hartmann, P. [et al.], 2015. Melting down: Systemic financial instability and the macroeconomy. http://dx.doi.org/10.2139/ssrn.2462567

52. Hatzius, J. [et al.], 2010. Financial Conditions Indexes: A New Look after the Financial Crisis. NBER Working Paper 16150. http://dx.doi.org/10.3386/w16150

53. Havránek, T., Horváth, R. and Matějů, J., 2012. Monetary Transmission and the Financial Sector in the Czech Republic. Economic Change and Restructuring, 45(3), pp. 135-155. https://doi.org/doi:10.1007/s10644-011-9106-z

54. He, Z. and Krishnamurthy, A., 2019. A Macroeconomic Framework for Quantifying Systemic Risk. American Economic Journal: Macroeconomics, 11(4), pp. 1-37. https://doi.org/doi:10.1257/mac.20180011

55. Hollo, D., Kremer, M. and Lo Duca, M., 2012. CISS - A composite indicator of systemic stress in the financial system. ECB Working Paper, No 1426.

56. Hoven, L. and Schreus, G., 2013. Towards a monthly indicator of economic growth. Report. Paper prepared for the Joint EU/OECD Workshop on Recent Developments in Business and Consumer Surveys, Brussels, 14-15 November 2013.

57. Hsiao, C., 1982. Autoregressive modeling and causal ordering of economic variables. Journal of Economic Dynamics and Control, 4, pp. 243-259. https:// doi.org/doi:10.1016/0165-1889(82)90015-x

58. Hubrich, K. and Tetlow, R. J., 2014. Financial stress and economic dynamics the transmission of crises. ECB Working paper, No 1728.

59. Huotari, J., 2015. Measuring Financial Stress - A Country Specific Stress Index for Finland (March 11, 2015). Bank of Finland Research Discussion Paper, No. 7/2015. http://dx.doi.org/10.2139/ssrn.2584378

60. Jahn, N. and Kick, T., 2012. Early warning indicators for the German banking system: a macroprudential analysis. Deutsche Bundesbank. Discussion paper, No. 27/2012.

61. Jermann, U. and Quadrini, V., 2012. Macroeconomic Effects of Financial Shocks. American Economic Review, 102(1), pp. 238-271. https://doi.org/ doi:10.1257/aer.102.1.238

62. Jin, X. and Nadal De Simone, F., 2020. Monetary policy and systemic risktaking in the Euro area investment fund industry: A structural factor-augmented vector autoregression analysis. Journal of Financial Stability, 49(C), 100749. https://doi.org/doi:10.1016/j.jfs.2020.100749

63. Jordá, O., Schularick, M. and Taylor, A. M., 2011. Financial Crises, Credit Booms, and External Imbalances: 140 Years of Lessons. IMF Economic Review, 59(2), pp. 340-378. https://doi.org/doi:10.1057/imfer.2011.8

64. Keynes, J., 1936. The General Theory of Employment, Interest and Money. London: Macmillan.

65. Kiyotaki, N. and Moore, J., 1997. Credit cycles. Journal of Political Economy, 105(2), pp. 211-248. https://doi.org/doi:10.1086/262072 
66. Koop, G., Pesaran, H. M. and Potter, S., 1996. Impulse response analysis in nonlinear multivariate models. Journal of Econometrics, 74(1), pp. 119-147. https://doi.org/doi:10.1016/0304-4076(95)01753-4

67. Kremer, M., 2015. Macroeconomic effects of financial stress and the role of monetary policy: a VAR analysis for the euro area. International Economics and Economic Policy, 13(1), pp. 105-138. https://doi.org/doi:10.1007/s10368-015-0325-z

68. Kremer, M. and Chavleishvili, S., 2021. Measuring Systemic Financial Stress and its Impact on the Macroeconomy. Beiträge zur Jahrestagung des Vereins für Socialpolitik 2021: Climate Economics. ZBW - Leibniz Information Centre for Economics, Kiel, Hamburg.

69. Li, F. and St-Amant, P., 2010. Financial Stress, Monetary Policy, and Economic Activity. Bank of Canada, Working Paper, No. 2010-12.

70. Linnemann, L. and Winkler, R., 2016. Estimating nonlinear effects of fiscal policy using quantile regression methods. Oxford Economic Papers, 68(4), pp. 1120-1145. https://doi.org/doi:10.1093/oep/gpw020

71. Lütkepohl, H., 1993. Introduction to Multiple Time Series Analysis, 2 ${ }^{\text {nd }}$. ed., Berlin: Springer-Verlag.

72. Lütkepohl, H., 2006. New Introduction to Multiple Time Series Analysis. Berlin: Springer.

73. Lütkepohl, H., 2010. Vector Autoregressive Models. Economics Working Paper, ECO 2011/30.

74. Lütkepohl, H., 2011. Vector Autoregressive Models. EUI Working Papers, ECO 2011/30.

75. Mallick, S. K. and Sousa, R. M., 2013. The real effects of financial stress in the Eurozone. International Review of Financial Analysis, 30, pp. 1-17. https://doi.org/doi:10.1016/j.irfa.2013.05.003

76. Marini, M., 2016. Nowcasting Annual National Accounts with Quarterly Indicators: An Assessment of Widely Used Benchmarking Methods. IMF Working paper, WP/16/71.

77. Martins, D., 2020. Euro Area Monetary Policy and Financial Stress Regimes: A Threshold VAR Approach. A Work Project, presented as part of the requirements for the Award of a Master Degree in Economics from the NOVA School of Business and Economics.

78. Misina, M. and Tkacz, G., 2008. Credit, Asset Prices, and Financial Stress in Canada. Working paper of Bank of Canada, 2008-10.

79. Mittnik, S. and Semler, W., 2013. The Real Consequences of Financial Stress. Center for Quantitative Risk Analysis (CEQURA). Working paper, No. 7.

80. Mittnik, S. and Semmler, W., 2013. The real consequences of financial stress. Journal of Economic Dynamics and Control, 37(8), pp. 1479-1499. https:// doi.org/doi:10.1016/j.jedc.2013.04.014

81. Mönch, E. and Uhlig, H., 2005. Towards a Monthly Business Cycle Chronology for the Euro Area. Journal of Business Cycle Measurement and Analysis, 1, pp. 43-58. 
82. Montes-Rojas, G., 2019. Multivariate quantile impulse response functions. Journal of Time Series Analysis, 40(5), pp. 739-752. https://doi.org/doi:10.1111/ jtsa. 12452

83. Neftci, S. N., 1984. Are Economic Time Series Asymmetric Over the Business Cycle?. Journal of Political Economy, 92(2), pp. 307-328. https://doi. org/10.1086/261226

84. Pesaran, M. H. and Shin, Y., 1998. Generalized impulse response analysis in linear multivariate models. Economics Letters, 58(1), pp. 17-29. https://doi. org/doi:10.1016/s0165-1765(97)00214-0

85. Sax, C. and Steiner, P., 2013. Temporal Disaggregation of Time Series. The $R$ Journal, 5(2), pp. 80-88. https://doi.org/doi:10.32614/rj-2013-028

86. Schmidt, R. H., 2019. On the change of the German financial system. SAFE White Paper, No. 61.

87. Schularick, M. and Taylor, A. M., 2012. Credit Booms Gone Bust: Monetary Policy, Leverage Cycles, and Financial Crises, 1870-2008. American Economic Review, 102(2), pp. 1029-1061. https://doi.org/doi:10.1257/aer.102.2.1029

88. Schüler, Y. S., 2014. Asymmetric Effects of Uncertainty over the Business Cycle: A Quantile Structural Vector Autoregressive Approach. University of Konstanz Working Paper Series, No. 2014-02.

89. Senapati, M. and Kavediya, R., 2020. Measuring Financial Stress in India. Department of Economic and Policy Research. Reserve Bank of India, WPS (DEPR), No. 09/2020.

90. Škrinjarić, T. and Šego, B., 2019. Risk connectedness of selected CESEE stock markets: a spillover index approach. China Finance Review International, 10(4), pp. 447-472. https://doi.org/doi:10.1108/cfri-07-2019-0124

91. Tamási, B. and Világi, B., 2011. Identification of credit supply shocks in a Bayesian SVAR model of the Hungarian Economy. MNB Working Papers, 7, pp. 1-21.

92. Van Aarle, B., Garretsen, H. and Gobbin, N., 2003. Monetary and fiscal policy transmission in the Euro-area: evidence from a structural VAR analysis. $4^{\text {th }}$ Eurostat and DG Ecfin colloquium on modern tools for business cycle analysis growth and cycle in the Euro-zone.

93. Van Roye, B., 2011. Financial Stress and Economic Activity in Germany and the Euro Area. Kiel Working Paper, No. 1743.

94. Van Roye, B., 2014. Financial stress and economic activity in Germany. Empirica, 41, pp. 101-126. https://www.doi.org/10.1007/s10663-013-9224-0

95. White, H., Kim, T. H. and Manganelli, S., 2015. VAR for VaR: Measuring tail dependence using multivariate regression quantiles. Journal of Econometrics, 187(1), pp. 169-188. https://doi.org/doi:10.1016/j.jeconom.2015.02.004

96. Yarovaya, L., Brzeszczyński, J. and Lau, C. K. M., 2016. Intra- and interregional return and volatility spillovers across emerging and developed markets: Evidence from stock indices and stock index futures. International Review of FinancialAnalysis,43,pp.96-114.https://doi.org/doi:10.1016/j.irfa.2015.09.004

97. Zaghini, A., 2016. Fragmentation and heterogeneity in the euro-area corporate bond market: Back to normal?. Journal of Financial Stability, 23(C), pp. 51-61. https://doi.org/doi:10.1016/j.jfs.2016.01.009 


\section{TABLE A1}

Unit root test results for all variables in the model

\begin{tabular}{|c|c|c|}
\hline & Level, type $=$ drift & Test values $1 \%, 5 \%, 10 \%$ \\
\hline DIIP & -3.219 & \multirow{5}{*}{$-3.46 ;-2.87 ;-2.57$} \\
\hline DHICP & -2.933 & \\
\hline IRATE & -1.293 & \\
\hline DLN & -3.396 & \\
\hline CISS & -3.881 & \\
\hline $\begin{array}{l}\text { DIRATE (differenced } \\
\text { interest rate) }\end{array}$ & $\begin{array}{r}\text { Type }=\text { none } \\
-3.488\end{array}$ & $-2.574 ;-1.942 ;-1.616$ \\
\hline
\end{tabular}

Note: Schwartz information criterion was used for the ADF test results. The KPSS test value for IRATE is equal to 1.65, with the critical values for $1 \%, 5 \%$ and $10 \%$ of $0.739,0.463$ and 0.347 respectively.

Source: Author's calculation.

\section{Figure A1}

Total spillover indices, $h=12$, rolling windows 30, 36 and 42 months, DGDP compared to DIIP

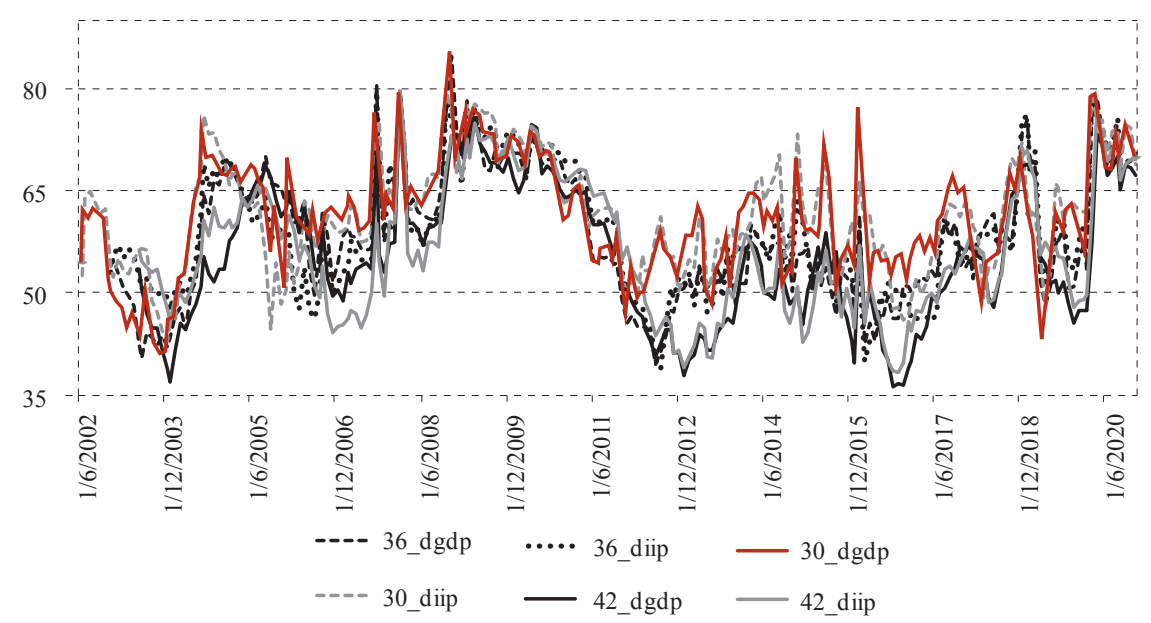

Source: Author's calculation. 


\section{Figure A2}

Net spillover indices between each variable and CISS, $h=12$, rolling windows 36 months, DGDP compared to DIIP
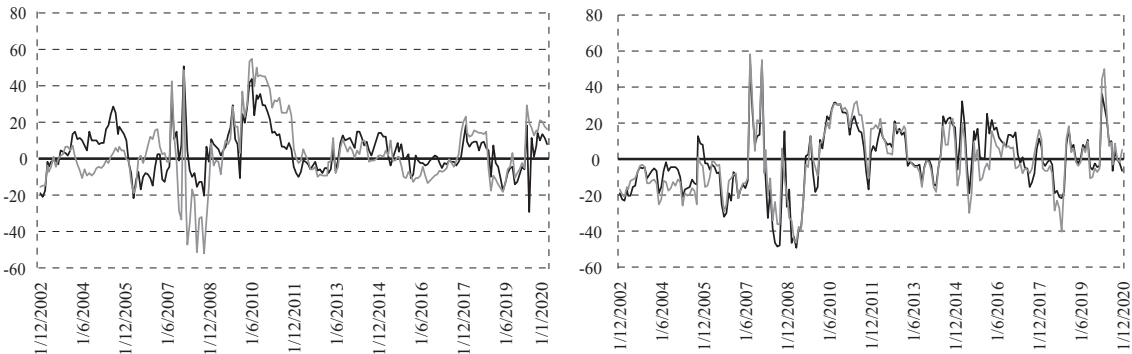

— dgdp_gdp _ diip_iip

— dhicp_gdp — dhicp_iip
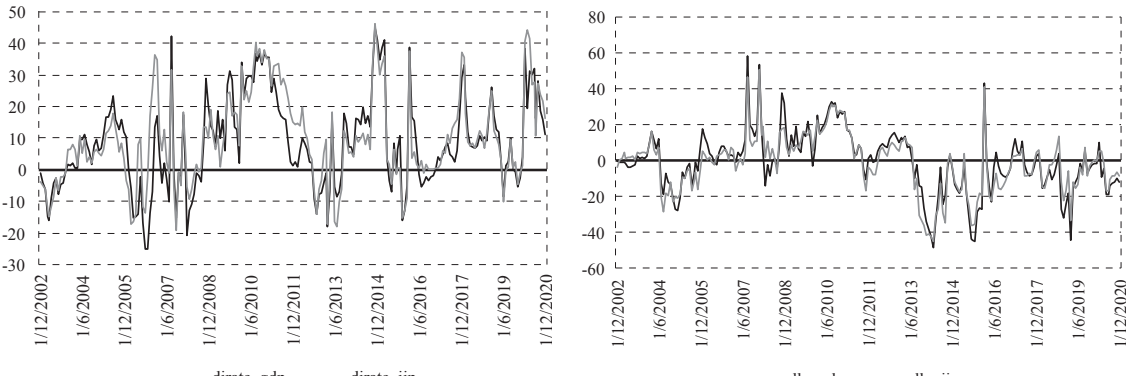

Source: Author's calculation.

\section{Figure A3}

Pair-wise net spillover indices between each variable and CISS, $h=12,18$ and 24, rolling windows 36 months, DIIP
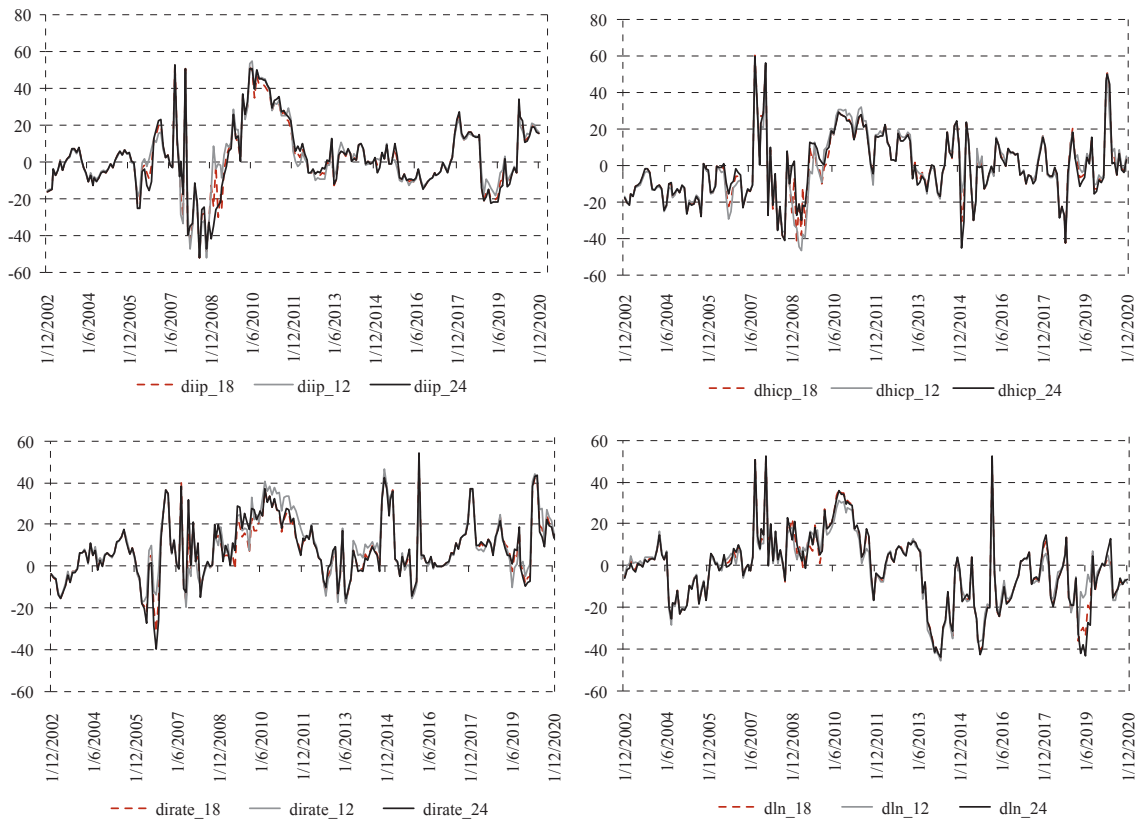

Source: Author's calculation. 
Figure A4

Correlation between CISS and selected variables, rolling windows 30, 36 and 42 months

30 months

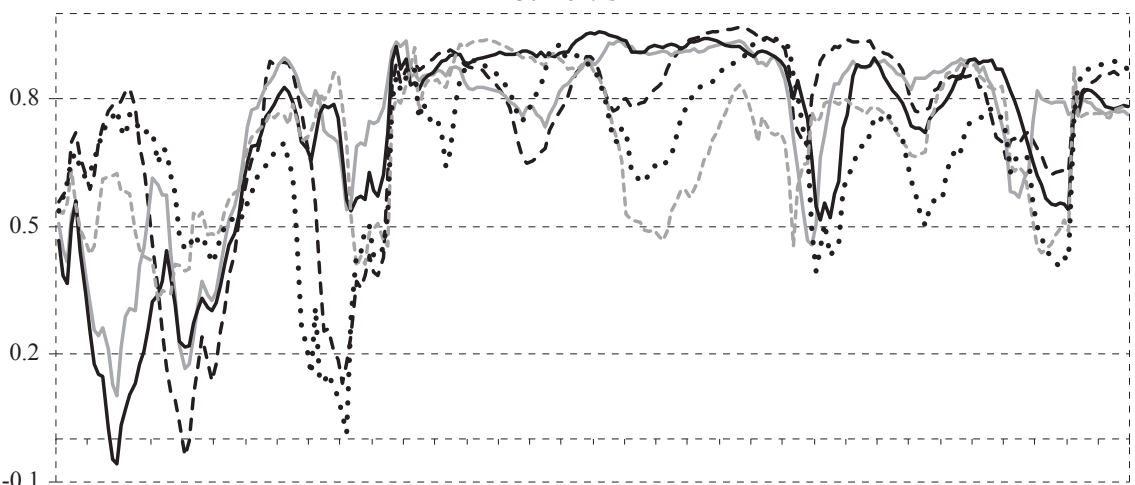

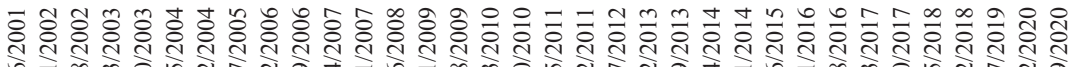

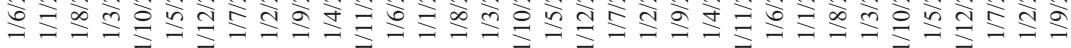

- - - Bond

Equity

Intermediaries

-..- FX

-... Money market

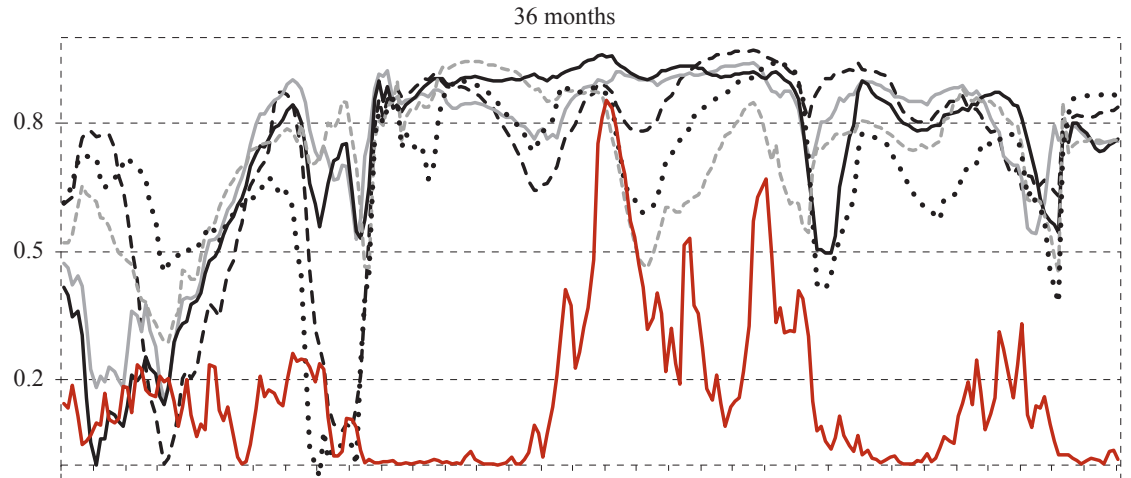
$-0.1$

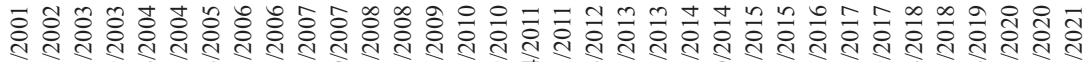

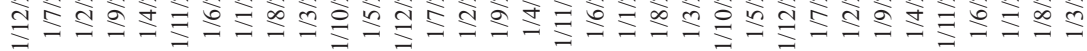

-- Bond — Equity — Intermediaries - - FX $\ldots$ Money market — Ciss 


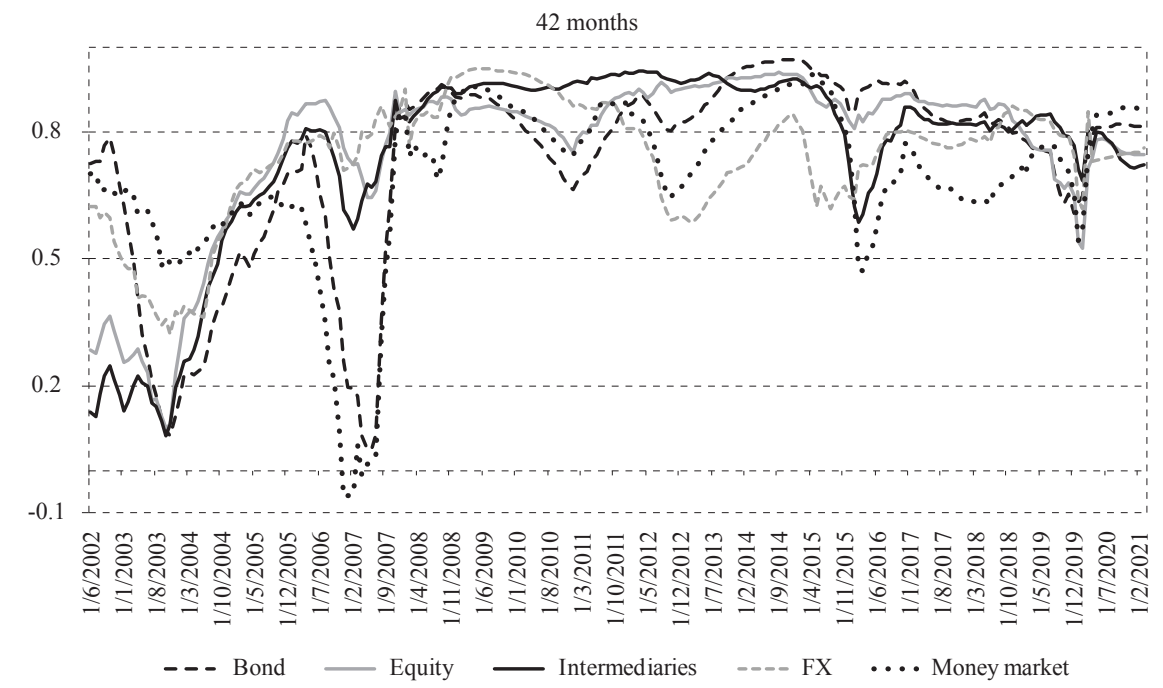

Note: Money market represents the realised volatility of the 3-month Euribor rate, interest rate spread between 3-month Euribor and 3-month T-bills, and monetary Financial Institutions (MFI) emergency lending at Eurosystem central banks; Intermediaries represents realised volatility of the idiosyncratic equity return of the Datastream bank sector stock market index over the total, yield spread btw A-rated fin. \& non-fin. corp. (7y), CMAX for the Datastream non-fin. sector stock market index interacted with the inverse price-book ratio for the fin. sector eqty. market index; $F X$ is the realised volatility of the euro exchange rate vis-a-vis the US dollar, the Japanese Yen and the British Pound; Equity is realised volatility of the Datastram non-financial sector stock market index, CMAX for the Datastream non-financial sector stock market index, and stock-bond correlation; and Bond is realised volatility of the German 10-year benchmark government bond index, yield spread between A-rated non-financial corporations and government bonds (7-year maturity bracket), and 10-year interest rate swap spread.

Source: Author's calculation. 
Figure A5

Generalized IRFs from VAR model, entire sample, reaction of CISS to shocks in other variables and reactions of others to shocks in CISS
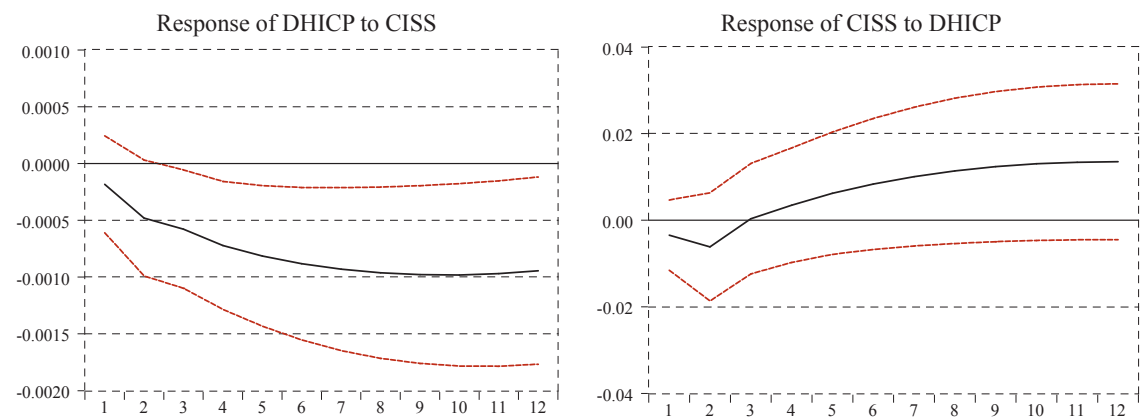

Response of DIIP to CISS
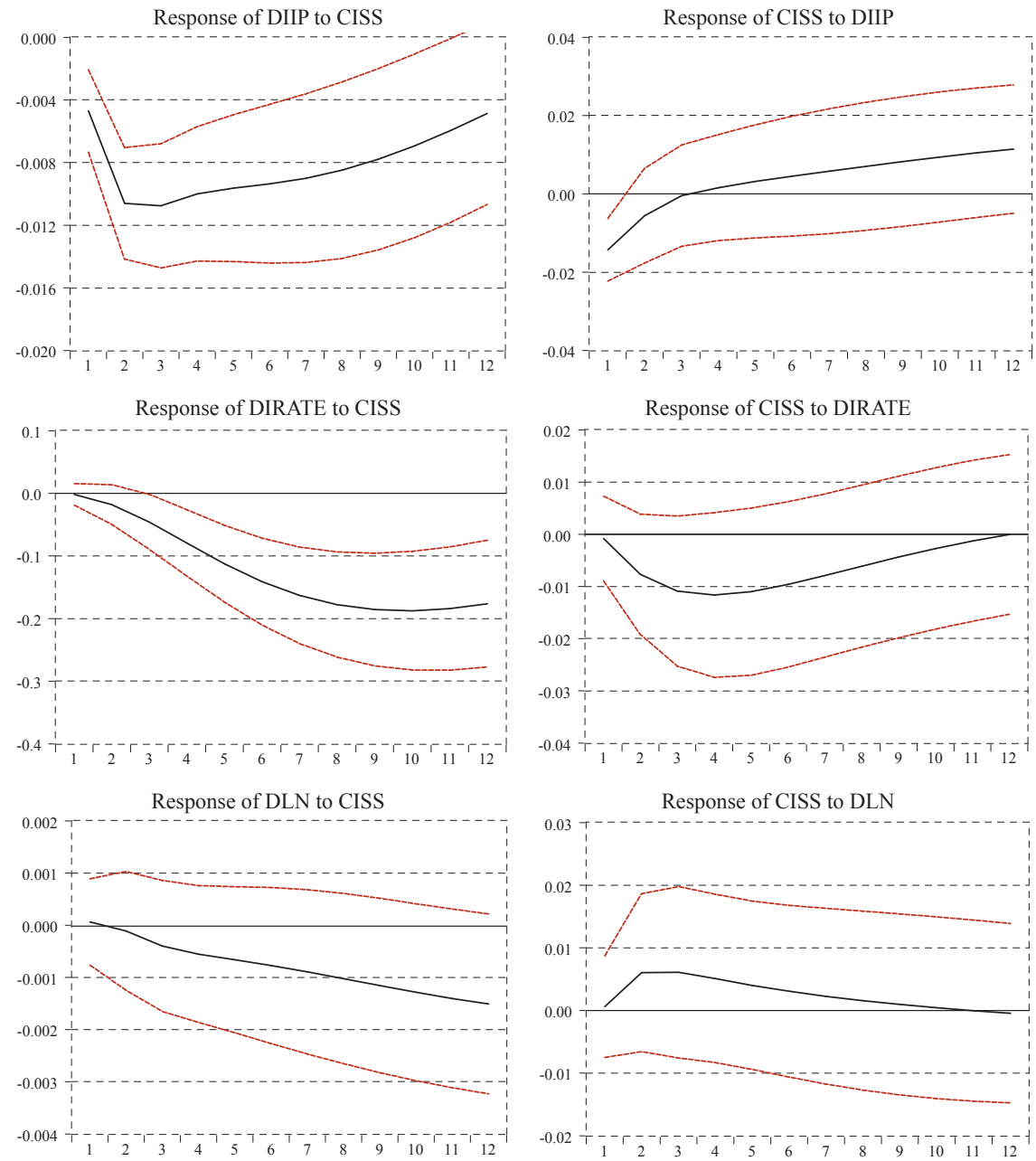

Note: Black curve denotes estimated impulse response and red dashed curves denote the $95 \%$ confidence interval.

Source: Author's calculation. 
Figure A6

SVAR IRFS, entire sample, reaction of CISS to shocks in other variables and reactions of others to shocks in CISS
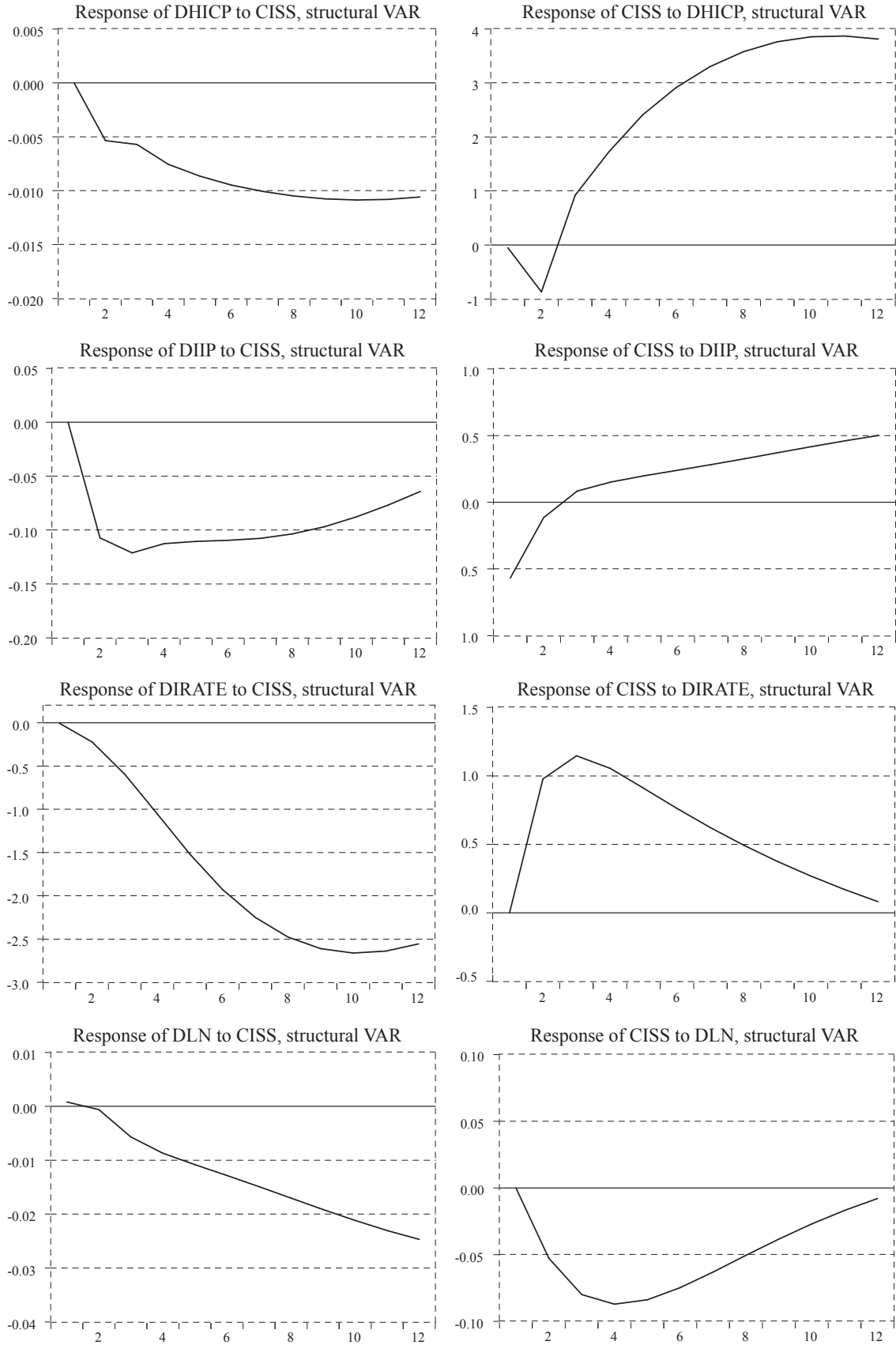

Note: $A u_{t}=B \varepsilon_{t}$ is the setting within the SVAR, where matrix $B$ is the unit matrix, and matrix $A$ has unit values on its diagonal with null values above the diagonal, and the rest of the values below the diagonal estimated in the analysis.

Source: Author's calculation. 